OPEN ACCESS

Edited by:

Mitsuo Tagaya,

Tokyo University of Pharmacy and Life

Sciences, Japan

Reviewed by:

Tamas Balla,

National Institutes of Health $(\mathrm{NIH})$,

United States

Thomas Simmen,

University of Alberta, Canada

*Correspondence:

Sima Lev

sima.lev@weizmann.ac.l

${ }^{t}$ These authors have contributed

equally to this work

Specialty section:

This article was submitted to

Membrane Traffic,

a section of the journal

Frontiers in Cell and Developmental

Biology

Received: 23 September 2019

Accepted: 16 December 2019

Published: 23 January 2020

Citation:

Peretti D, Kim SH, Tufi R and

Lev S (2020) Lipid Transfer Proteins and Membrane Contact Sites

in Human Cancer.

Front. Cell Dev. Biol. 7:371

doi: 10.3389/fcell.2019.00371

\section{Lipid Transfer Proteins and Membrane Contact Sites in Human Cancer}

\author{
Diego Peretti ${ }^{1+}$, SoHui Kim ${ }^{2 t}$, Roberta Tufi ${ }^{3 t}$ and Sima Lev4* \\ ${ }^{1}$ UK Dementia Research Institute, Clinical Neurosciences Department, University of Cambridge, Cambridge, \\ United Kingdom, ${ }^{2}$ Nakseongdae R\&D Center, GPCR Therapeutics, Inc., Seoul, South Korea, ${ }^{3}$ MRC Mitochondrial Biology \\ Unit, University of Cambridge, Cambridge, United Kingdom, ${ }^{4}$ Molecular Cell Biology Department, Weizmann Institute \\ of Science, Rehovot, Israel
}

Lipid-transfer proteins (LTPS) were initially discovered as cytosolic factors that facilitate lipid transport between membrane bilayers in vitro. Since then, many LTPs have been isolated from bacteria, plants, yeast, and mammals, and extensively studied in cell-free systems and intact cells. A major advance in the LTP field was associated with the discovery of intracellular membrane contact sites (MCSs), small cytosolic gaps between the endoplasmic reticulum (ER) and other cellular membranes, which accelerate lipid transfer by LTPs. As LTPs modulate the distribution of lipids within cellular membranes, and many lipid species function as second messengers in key signaling pathways that control cell survival, proliferation, and migration, LTPs have been implicated in cancerassociated signal transduction cascades. Increasing evidence suggests that LTPs play an important role in cancer progression and metastasis. This review describes how different LTPs as well as MCSs can contribute to cell transformation and malignant phenotype, and discusses how "aberrant" MCSs are associated with tumorigenesis in human.

Keywords: LTPs, MCSs, cancer, calcium, lipids

\section{INTRODUCTION}

Lipid-transfer proteins (LTPs) are highly conserved lipid carriers that bind monomeric lipids in a hydrophobic pocket, and transfer them between donor and acceptor membranes through an aqueous phase (Zilversmit, 1983; Holthuis and Levine, 2005). Based on their lipid binding specificity, LTPs can be divided into several subgroups including: (1) sphingolipid-, (2) sterol-, and (3) phospholipid-transfer proteins (Lev, 2010). A close proximity between the donor and the acceptor membranes, as occurs at MCSs, reduces the diffusion distance of LTPs and accelerates intermembrane lipid transport. Although LTPs were discovered in the late 1970s (Wirtz, 1974; Wirtz et al., 1980) and MCSs already observed by electron microscopy in the 1950s (Porter, 1953), their physiological functions and regulatory properties have only been emerged in the last few years (Levine, 2004; Selitrennik and Lev, 2016).

Numerous studies on LTPs and MCSs from the last five years highlighted their important roles in regulating intracellular lipid distribution and signaling, and demonstrated the diversity of MCSs, their dynamics, tethering mechanisms, and various physiological functions (Saheki and De Camilli, 2017). These studies suggest that LTPs and MCSs are involved in central cellular processes, 
including cell growth and migration, cellular metabolism, and proteostasis (Sassano et al., 2017). Abnormal regulation of these processes is frequently associated with tumorigenesis, implying that LTPs and MCSs can contribute to tumor development and metastasis.

Indeed, increasing evidence suggests that LTPs can modulate local lipid composition of membranes, and thus, influence their biophysical properties (fluidity, curvature) as well as the content of lipid second messengers (van Meer, 1993; Levine, 2007; Van Meer et al., 2008). Of the various lipid second messengers, phosphoinositides, and in particular, phosphatidylinositol-3,4,5trisphosphate $\left(\mathrm{PIP}_{3}\right)$ and its precursor phosphatidylinositol4,5-bisphosphate $\left(\mathrm{PIP}_{2}\right)$ are tightly associated with human cancer (Toker, 2002; Brown and Toker, 2015). Other signaling lipids such as sphingolipids and fatty acids also play a role in cancer progression and metastasis (Luo et al., 2018), and further information on the function of lipids and lipid metabolism in cancer can be found elsewhere (Murai, 2015; Kim et al., 2016; Long et al., 2018). In this review, we discuss the role of several LTPs, including phosphatidylinositol (PI)transfer proteins (PITPs) and steroidogenic acute regulatory protein (StAR)-related lipid transfer (START family) (Soccio and Breslow, 2003; Alpy and Tomasetto, 2005) in human cancer, and further describe the heterogeneity of MCSs, their function in lipid transport and calcium signaling, and their implication in cancer biology. Additional information related to LTPs and MCSs had been previously described in many excellent reviews and are not covered here (Cohen et al., 2018; Prinz et al., 2019; Scorrano et al., 2019; Wong et al., 2019).

\section{PHOSPHOINOSITIDES AND CANCER}

All phosphoinositides are derivatives of PI, a phospholipid that is synthesized in the ER and is composed of a hydrophobic diacylglycerol (DAG) coupled to inositol 1-monophosphate ring (Lev, 2012). Phosphorylation of the inositol ring at its 3, 4, and 5 hydroxyl groups, either at single site or in combination, results in the seven different phosphorylation states of membrane phosphoinositides, including PI3P, PI4P, PI5P, $\mathrm{PI}(3,4) \mathrm{P}_{2}, \mathrm{PI}(3,5) \mathrm{P}_{2}, \mathrm{PI}(4,5) \mathrm{P}_{2}$, and $\mathrm{PI}(3,4,5) \mathrm{P}_{3}$. These phosphoinositides are distinctly distributed between intracellular organelles and play different cellular functions (Balla, 2013). $\mathrm{PI}(3) \mathrm{P}$ and $\mathrm{PI}(3,5) \mathrm{P}_{2}$ are considered as endolysosomal species, PI4P is enriched in the trans-Golgi network (TGN) and PI5P within the nuclei, whereas $\mathrm{PI}(4,5) \mathrm{P}_{2}, \mathrm{PI}(3,4) \mathrm{P}_{2}$, and $\mathrm{PI}(3,4,5) \mathrm{P}_{3}$ are mainly found at the plasma membrane (PM) (De Craene et al., 2017). The production and maintenance of these different phosphoinositides is mediated by a network of interconverting enzymes including phosphoinositide-specific kinases and phosphatases.

Although phosphoinositides are minor phospholipids of the $\mathrm{PM}, \mathrm{PI}(4,5) \mathrm{P}_{2}$, which plays a central role in cellular signaling, is considered to be the most abundant. It undergoes rapid hydrolysis by phospholipase $\mathrm{C}$ (PLC) in response to multiple external stimuli to generate DAG and inositol-1,4,5trisphosphate $\left(\mathrm{IP}_{3}\right)$ second messengers. In addition, it binds to proteins that regulate actin polymerization, cell adhesion and cell-cell contact, and consequently affects cancer cell motility (Bunney and Katan, 2010). Most importantly, PI(4,5) $\mathrm{P}_{2}$ is phosphorylated by $\mathrm{PI} 3 \mathrm{~K}$ (phosphatidylinositol 3-kinase) to generate $\mathrm{PI}(3,4,5) \mathrm{P}_{3}$, an important phosphoinositide that regulates cell survival, proliferation and growth. $\mathrm{PI}(3,4,5) \mathrm{P}_{3}$ can be dephosphorylated by the $3^{\prime}$-phosphatase PTEN to terminate PI3K signaling. Notably, activating mutations in the catalytic domain of PI3K, i.e., PIK3CA, and loss-of-function mutations in PTEN are among the most common genetic alterations found in human cancer, demonstrating the central role of this phosphoinositide in cancer biology (Engelman, 2009). In addition, AKT which is activated by $\operatorname{PI}(3,4,5) \mathrm{P}_{3}$, is amplified, overexpressed or hyperactivated in multiple human cancers (Altomare and Testa, 2005). Given the central role of $\mathrm{PI}(3,4,5) \mathrm{P}_{3}$ in human cancer, it is not surprising that inhibition of $\mathrm{PI}(3,4,5) \mathrm{P}_{3}$ production and/or its downstream effectors utilizing kinase inhibitors to PI3K, AKT, or mTOR (mechanistic target of rapamycin) have been utilized as promising strategies for cancer therapy (Engelman, 2009).

Recent studies, however, suggested that several phosphoinositide-transfer proteins also regulate $\mathrm{PI}(3,4,5) \mathrm{P}_{3}$ levels and are implicated in cancer progression and metastasis. We discuss a few examples including, $\operatorname{PITP} \alpha$ and $\beta, \operatorname{Nir} 2$, PITPNC1, and TIPE3.

\section{PITPs}

In humans, there are five PITPs that can be classified into two major groups: small PITPs, which include $\operatorname{PITP} \alpha, \operatorname{PITP} \beta$, and PITPNC1, and large multi-domains proteins including Nir2 and Nir3 (Figure 1A; Lev, 2004). The PI-transfer domain is highly conserved in all human PITPs and can transfer PI and phosphatidylcholine (PC), whereas few PITPs can also transfer phosphatidic acid (PA) and sphingomyelin (SM) (Li et al., 2002; Yadav et al., 2015).

The involvement of PITP $\alpha$ and $\beta$ in phosphoinositides production, turnover and signaling has been demonstrated by many studies employing reconstituted systems, cell-free assays and intact cells. Collectively, these studies showed that $\mathrm{PITP} \alpha$ and $\beta$ can enhance $\mathrm{PI}(4,5) \mathrm{P}_{2}$ and $\mathrm{PI}(3,4,5) \mathrm{P}_{3}$ production (Cockcroft and Garner, 2013). In addition, it was shown that overexpression of PITP $\alpha$ in mouse fibroblasts markedly enhanced cell proliferation (Schenning et al., 2004), and that depletion of Nir2 by shRNA substantially reduced $\mathrm{PI}(4,5) \mathrm{P}_{2}$ levels at the plasma membrane and consequently $\mathrm{PI}(3,4,5) \mathrm{P}_{3}$ production in response to growth factor stimulation (Chang et al., 2013; Kim et al., 2013; Chang and Liou, 2015). Low levels of these phosphoinositide second messengers were accompanied by reduced AKT and ERK1/2 phosphorylation, and as a result, inhibition of cell migration and invasion (Keinan et al., 2014). Nir2 depletion markedly attenuated the migration and invasion of mammary epithelial cells and human breast carcinoma and induced mesenchymal-to-epithelial transition (MET) of highly metastatic breast cancer cells. Consistent with these findings, we showed that Nir2 level was upregulated during EMT, and its depletion in breast cancer blocked lung metastasis in animal models (Keinan et al., 2014). We also observed high correlation 
A PI-transfer proteins

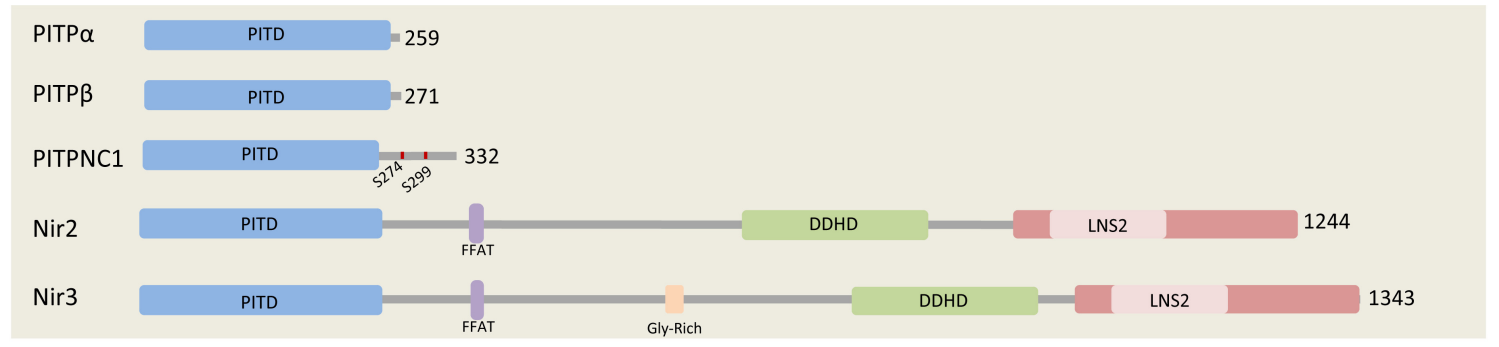

B PIP2, PIP3 transfer protein

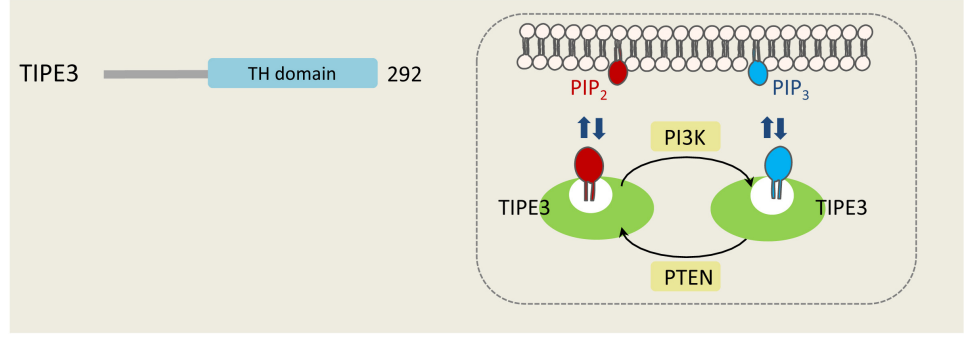

FIGURE 1 | Phosphatidylinositols transfer proteins. (A) PI-transfer proteins. The five human PI-transfer proteins can be divided into small proteins consisting of a single PI-transfer domain (PITD) including PITP $\alpha / \beta$ and PITPNC1, and the multi-domains containing proteins Nir2 and Nir3. Shown are the PITD, the FFAT motif, DDHD, and the C-terminal LNS2 (Lipin/Nde1/Smp2) domain. Glycine rich region is found only in Nir3 (Lev, 2004). PITPNC1 phosphorylation sites (S274 and S299), which bind 14-3-3, are represented as red dots on PITPNC1 protein (Halberg et al., 2016). (B) TIPE3, a $\mathrm{PIP}_{2}$, and $\mathrm{PIP}_{3}$ transfer protein. TIPE is the only protein that is known to transfer phosphoinositides. It preferentially binds $\mathrm{PIP}_{2}$ and $\mathrm{PIP}_{3}$, and contributes to increase their levels at the PM by mediating efficient supply of $\mathrm{PIP} 2$ and presenting it to PI3K to produce $\mathrm{PIP}_{3}$ (Fayngerts et al., 2014). The numbers at the right side of each protein indicate the length of each protein in amino acids.

between Nir2 expression and tumor grade as well as poor disease outcome of breast cancer patients.

PITPNC1 is also implicated in cancer metastasis, but in contrast to $\operatorname{PITP} \alpha$ and $\beta$, has a unique $\mathrm{C}$-terminal extension with two serine phosphorylation sites, which provide docking sites for 14-3-3 protein (Garner et al., 2011). It was proposed that 14-3-3 binding protects PITPNC1 from degradation and inhibits its lipid transfer activity (Cockcroft and Garner, 2012). While further studies should explore this hypothesis, currently there is strong evidence that PITPNC1 is associated with different human cancers. It is highly expressed in several cancers, and its overexpression significantly correlates with metastatic progression of breast, melanoma, and colon cancers. PITPNC1 was identified as a target gene of miR-126, a metastasis suppressor microRNA (Png et al., 2012). It is amplified in a large fraction of human breast cancers, and its depletion by shRNA markedly attenuated metastasis in animal models (Halberg et al., 2016). Mechanistic studies suggest that PITPNC1 binds PI4P and enhances the secretion of pro-invasive and pro-angiogenic mediators, through recruitment of RAB1B (Rasrelated protein Rab-1B) and the PI4P-binding protein GOLPH3 (Golgi phosphoprotein 3) to the TGN (Halberg et al., 2016). Interestingly, PITPNC1 was also found to bind and transfer PA but not PC (Garner et al., 2012), implying that it has unique lipid binding and/or transfer capabilities.

\section{TIPE3}

TIPE3 belongs to the TNFAIP8 (tumor necrosis factoralpha-induced protein 8 , or TIPE) family of proteins which are implicated in tumorigenesis and inflammation (Moniz and Vanhaesebroeck, 2014). It contains a C-terminal TIPE2 Homology (TH) domain, consisting of a large hydrophobic cavity that accommodates phospholipid molecules (Fayngerts et al., 2014). Similarly to the other TNFAIP8 members (TIPE1, TIPE2, and TNFAIP8), TIPE3 can bind a number of phosphoinositides, including $\mathrm{PI}(4,5) \mathrm{P}_{2}, \mathrm{PI}(3,5) \mathrm{P}_{2}, \mathrm{PI}(3,4) \mathrm{P}_{2}$, and $\mathrm{PI}(3,4,5) \mathrm{P}_{3}$. It preferentially captures and transfers $\mathrm{PI}(4,5) \mathrm{P}_{2}$ and $\mathrm{PI}(3,4,5) \mathrm{P}_{3}$ and increases their levels at the PM, thereby promoting AKT and ERK pathways activation (Fayngerts et al., 2014). It was proposed that TIPE3 functions as a lipid-presenting protein and enhances $\mathrm{PI}(3,4,5) \mathrm{P}_{3}$ production by $\mathrm{PI} 3 \mathrm{~K}$ (Figure 1B).

TIPE3 is highly expressed in several human cancers including lung, cervical, colon, esophageal and breast. Its overexpression enhances cell growth, migration and invasion in vitro and tumor growth in animal models, whereas its knockdown has opposite effects (Fayngerts et al., 2014; García-Tuñón et al., 2017). These observations suggest that TIPE3, and possibly its other family members, are a new class of phosphoinositide transfer proteins, which regulate tumor growth and progression.

\section{START PROTEINS AND THEIR INVOLVEMENT IN HUMAN CANCER}

In mammals, there are fifteen proteins containing the START (StAR-related lipid-transfer) domain, which can be grouped into six subfamilies according to sequence similarities and lipid binding specificities. The STARD1/D3 subfamily has specificity 


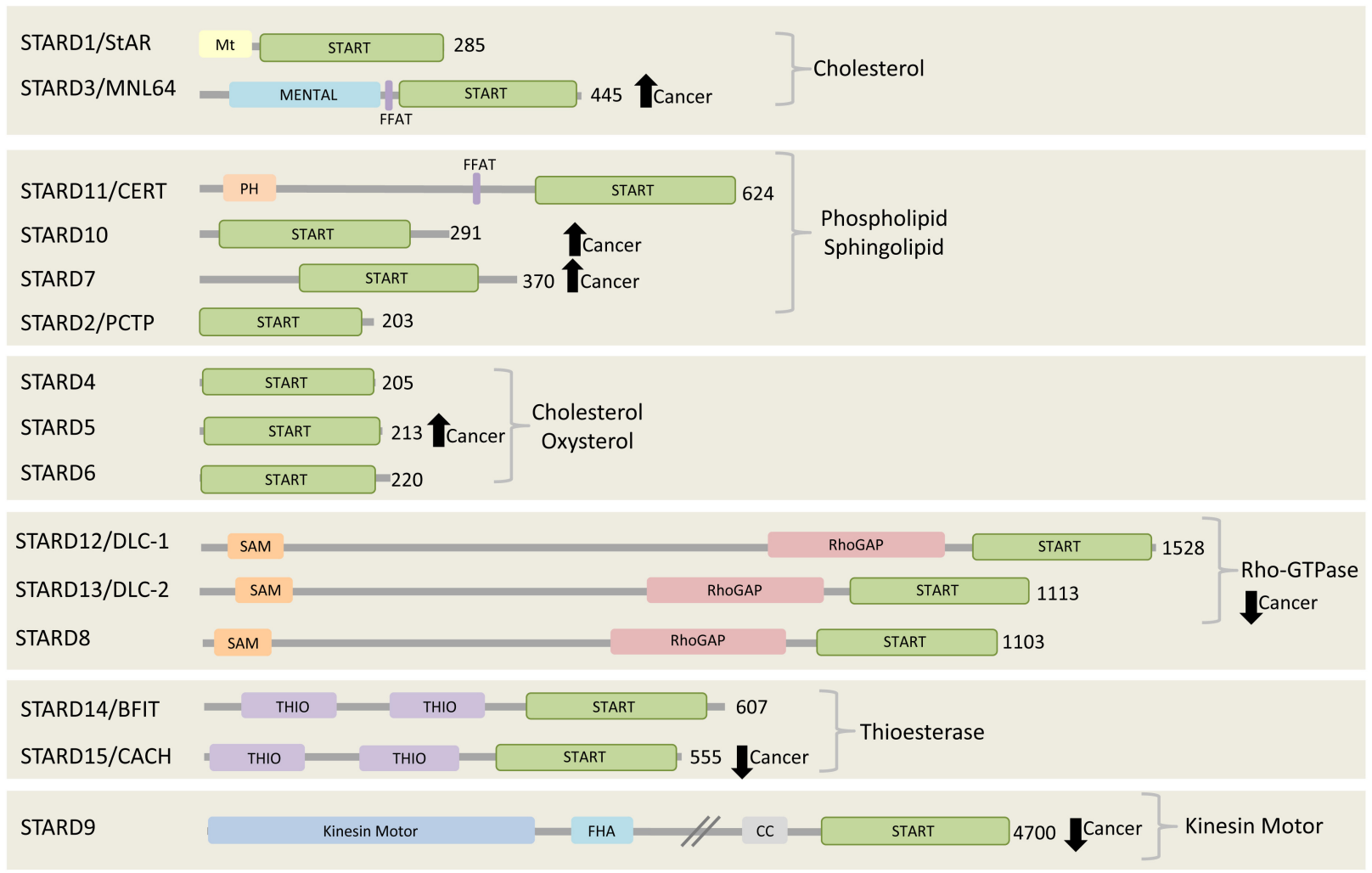

FIGURE 2 | The START proteins. Fifteen START proteins in human are grouped into six subfamilies. Three groups share the indicated lipid binding/transfer specificity of START domain, while the other three groups share the indicated functional domains. All members have their START domain at the C-terminal region. Among 15 START proteins, two of them, STARD3 and CERT, contain FFAT motif. STARD3, STARD10, STARD7, and STARD5 are found to be highly expressed and connected to poor prognosis in various cancers including breast cancer, gestational trophoblastic tumor (Clark, 2012). On the other hand, the expression of all members of Rho-GTPase subgroup, STARD8/12/13, STARD9, and STARD15 are reported to be decreased in cancer (Clark, 2012). The number at the right side of each C-terminal represents the length of each protein in amino acids.

for cholesterol, STARD4/D5/D6 subfamily for cholesterol or oxysterol, and STARD2(PCTP)/D7/D10/D11 subfamily for phospholipids or sphingolipids (Figure 2). The lipid-binding specificity of the other three subgroups is unknown, but they share other functional domains. STARD8/12/13 subfamily shares a putative Rho-GTPase domain, STARD14/15 subfamily has thioesterase activity, and STARD9 has a kinesin motor function (Alpy and Tomasetto, 2005). Interestingly, the START domain is always located at the C-terminal of the START proteins, possibly to facilitate lipid binding, transfer and release. Few START proteins contain membrane targeting motifs that mediate their interaction with different organelles. STARD1, for example, has a mitochondrial targeting motif and STARD3 has a MENTAL (MLN64 NH(2)-terminal) domain for late endosome (LE) targeting, while STARD11/CERT (ceramide transfer protein) contains a $\mathrm{PH}$ (pleckstrin homology) domain for PI4P binding at the Golgi complex. STARD3 and STARD11 both contain a FFAT (two phenylalanines in an acidic tract) motif between their N-terminal membrane targeting determinants and the C-terminal START domain (Figure 2). Almost all START proteins have been implicated in either in cancer progression or suppression (Olayioye et al., 2004, 2005; Durkin et al., 2007a,b; Clark, 2012; Vassilev et al., 2015). Here we focus on the FFAT motif-containing proteins, STARD3 and STARD 11, and discuss their role in cancer.

\section{STARD3}

STARD3 was originally named metastatic lymph node clone 64 protein (MLN64) since it was discovered in a screen designed to identify human genes that were amplified or overexpressed in aggressive breast tumor. The screen used subtractive hybridization method and identified clone number 64 as a gene that is overexpressed in all HER2 positive breast tumors (Tomasetto et al., 1995). Subsequently, it was shown to be coamplified and co-expressed with HER2 in various breast cancer cell lines and in about 10-25\% breast cancers (Bièche et al., 1996; Vassilev et al., 2015). STARD3 gene is located in the minimal amplicon of HER2-positive breast cancers. It is co-amplified with HER2 (Alpy et al., 2003) and always overexpressed with HER2 in breast cancer cells (Pollack et al., 1999; Perou et al., 2000; Vincent-Salomon et al., 2008).

Currently, it is unclear how STARD3 enhances tumorigenesis of HER2-positive breast cancer and how the two proteins cooperate. However, several possibilities could be postulated; STARD3, via its cholesterol transfer activity, plays a central role in redistribution of cholesterol between the ER and 


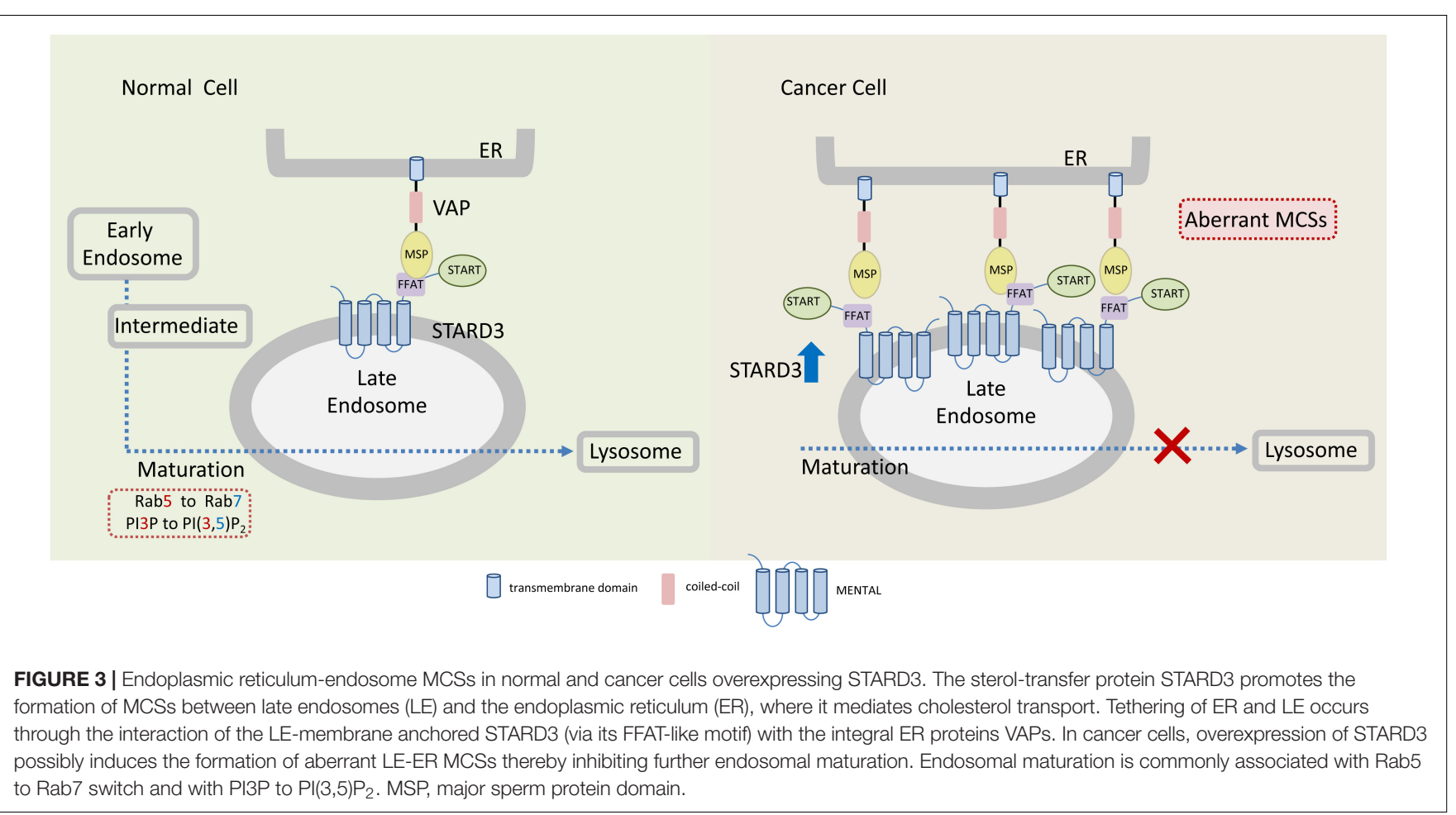

endosomes. It interacts with the ER via its FFAT motif and with endosome via its MENTAL domain (Figure 3). The MENTAL domain shares structural homology with tetraspanin superfamily consisting of four transmembrane helices. This domain does not have any typical late endosome (LE)-targeting motifs, however, mutagenesis analysis strongly suggests that the MENTAL domain is crucial for STARD3 targeting to LE (Alpy et al., 2013). When STARD3 is amplified or overexpressed in HER2-positive breast cancer, the endosomal membranes are wrapped by the ER, leading to rigid and static ER-LE MCSs, thus losing their transient and dynamic features. Interestingly, stacking of ER membranes is also observed by ectopic overexpression of LTP proteins containing FFAT motif together with vesicle-associated membrane protein-associated proteins (VAPs) which produces abnormal ER structures called karmellae (Amarilio et al., 2004). The ER-LE static structures might lock the LE and inhibit their maturation to lysosomes (Figure 3). Under these conditions, lysosomal degradation of cell surface receptors, including HER2 and other growth factors receptors would be impaired, receptors will be sorted back to the PM and signal termination will be prevented, leading to uncontrolled cell growth. In this way, STARD3 may enhance the progression of HER2-positive cancer. Indeed, it was shown that STARD3 overexpression increases the proliferation rates of HER2-positive breast cancer cells, while its knockdown has an opposite effect (Wilhelm et al., 2017).

\section{CERT (STARD11)}

CERT, a $68-\mathrm{kDa}$ cytosolic protein, also known as collagen type IV alpha-3-binding protein (Col4A3BP) or STARD11, transfers ceramide from the ER to the Golgi, where various modifications take place to produce complex sphingolipids
(Hanada et al., 2003). CERT via its $\mathrm{N}$-terminal PH domain binds PI4P at the Golgi and via its FFAT motif interacts with the ER-resident VAP proteins to transfer ceramide through the ERGolgi MCSs (Kawano et al., 2006; Peretti et al., 2008). The START domain of CERT is exclusively specific for ceramide. The significance of CERT in cell physiology and cancer progression is mainly associated with its ceramide transfer activity, as ceramide is a precursor of sphingolipids (Figure 4).

Sphingolipids are made up of a large class of lipid species having sphingosine as their backbone. They are involved in maintaining the structural integrity and fluidity of cell membranes and in regulating various cellular processes such as proliferation, migration, angiogenesis and inflammation (Kunkel et al., 2013; Morad and Cabot, 2013; Kreitzburg et al., 2018). Ceramide, an $\mathrm{N}$-acylated form of sphingosine, is the simplest type of sphingolipid; it serves as a precursor of more complex sphingolipids, including sphingomyelin (SM), glycosylceramide and ceramide 1-phosphate $(\mathrm{C} 1 \mathrm{P})$, which are produced at the Golgi by SMS (sphingomyelin synthase), UGCG (UDP-glucose ceramide glucosyltransferase) and CERK (ceramide kinase), respectively (Yamaji and Hanada, 2015).

Sphingomyelin, which is synthesized by SMS from PC and ceramide, is a key component of lipid rafts, affects membrane fluidity and is involved in signal transduction. Of note, CERT was first isolated as a factor that recovers SM levels in a SM-deficient cell line (Hanada et al., 2003). Glycosylceramide is synthesized by UGCG via transferring a glucose residue from UDP-glucose to ceramide. It serves as a precursor for lactosylceramide, which is the precursor of most of glycosphingolipids except galactosylceramide and its derivates. $\mathrm{C} 1 \mathrm{P}$ is a phosphorylated form of ceramide and it 


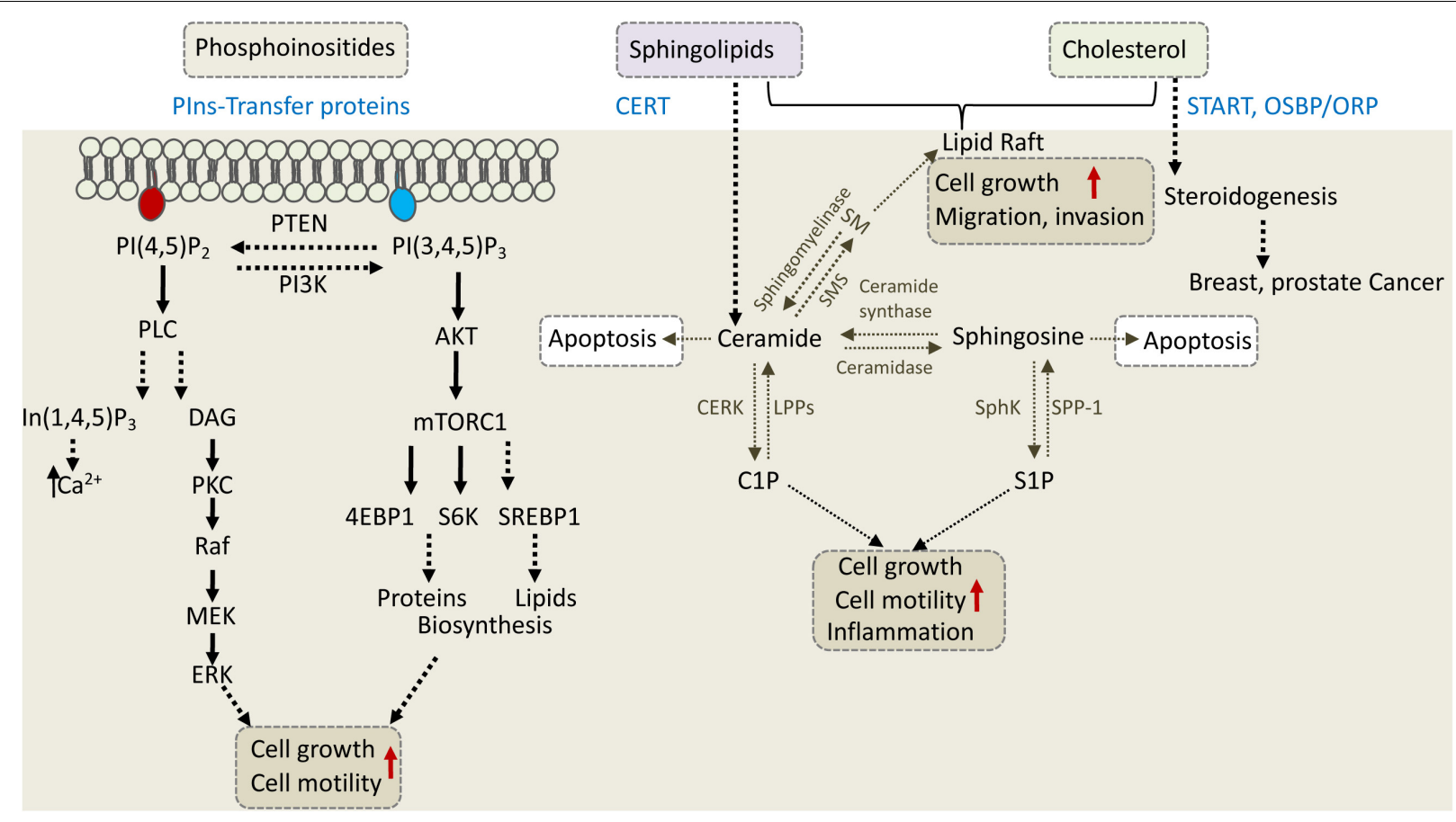

FIGURE 4 | Phosphoinositides, sphingolipids, and cholesterol regulate cell growth, motility, and invasion. The depicted cellular pathways are regulated by phosphoinositeds (PIns), sphingolipids, and cholesterol and can influence cell growth, motility, invasion, or apoptotic cell death. LTPs are labeled in blue and include PIns-transfer proteins, ceramide transfer protein (CERT), and various cholesterol transfer proteins of the START and OSBP/ORP family. PLC, phospholipase C; PKC, protein kinase C; DAG, diacylglycerol; S6K, S6 kinase; SM, sphingomyelin; SMS, SM synthase; S1P, sphingosine 1-phosphate; C1P, ceramide 1-phosphate; LPP, lipid phosphate phosphatase; SPP-1, S1P phosphatase-1; CERK, ceramide kinase; SphK, sphingosine kinase.

functions as an adaptor for type IVA cytosolic phospholipase A2 (cPLA2) to produce pro-inflammatory eicosanoids. Among the three sphingolipids, SM is mostly affected by CERT defects, although the other two are also influenced (Prestwich et al., 2008; Yamaji and Hanada, 2014, 2015).

The central role of ceramide in sphingolipid metabolism is also demonstrated in sphingosine-1-phosphate (S1P) pathway, which regulates multiple cellular processes such as proliferation, neovascularization, migration, and invasion. Ceramide, sphingosine and S1P comprise the three core lipids of S1P pathway, which are rapidly interconverted in response to various external stimuli such as growth factors, inflammation and stress. Ceramidase converts ceramide to sphingosine, which is further modified by SphK (sphingosine kinase) to S1P or reversed to ceramide by ceramide synthase (Figure 4). ABC transporters and Spns2 (spinster homolog 2) can export S1P outside the cell, where it binds to S1PR1 to 5 (sphingosine-1-phosphate receptor), and induces their signal transduction in both autocrine and paracrine manner (Spiegel and Milstien, 2003).

While ceramide induces apoptosis, its metabolites induce signaling cascades that promote cell proliferation or migration (Figure 4). Therefore, CERT can either promote or inhibit cancer progression depending on cellular context. In triple-negative breast cancer (TNBC), for example, CERT depletion promotes cancer progression (Heering et al., 2012). It was proposed that low levels of CERT in TNBC concomitant with reduced levels of SM and cholesterol at the PM, increased PM fluidity and caused high activation of EGFR (epidermal growth factor receptor) to enhance tumorigenesis (Heering et al., 2012). On the other hand, CERT depletion was beneficial for cancer therapy in colorectal and HER2-positive breast cancer cell line (Lee et al., 2012). CERT is highly expressed in HER2-positive breast cancer, and its depletion induced ceramide accumulation in the ER and concomitant changes in genes expression. One of the genes induced by CERT depletion was LAMP2 (lysosomal associated membrane protein-2) which mediated paclitaxel sensitization via induction of autophagic cell death (Lee et al., 2012). It appears that inhibition of CERT could lead to tumor suppression in some cancers and tumor progression in others, and thus could represent a potential target for precision medicine. Similar to CERT, other LTPs that regulate phosphoinositides, shingolipids and cholesterol can affect different signaling and metabolic pathways to enhance cell survival, growth and motility or to inhibit cell death, and consequently could affect cancer progression, metastasis and/or response to treatment (Figure 4).

\section{MEMBRANE CONTACT SITES}

MCSs are defined as small cytosolic gaps of $\sim 10-25 \mathrm{~nm}$ between the ER membranes and PM [plasma membrane-associated membranes (PAM)], the mitochondria [mitochondria-associated ER membranes (MAM)], or other intracellular organelles including endosomes, Golgi complex, peroxisomes, lysosomes 
and lipid droplets (Levine, 2004; Wong et al., 2018). These contact sites enable the transport of lipids, calcium ions and different metabolites by non-vesicular transport mechanisms, and thus, provide a platform for inter-organellar communication (Holthuis and Levine, 2005). MCSs are highly dynamic and heterogenous structures formed by specialized tethering proteins that bridge two membrane compartments (Lev, 2010). Multiple organellespecific tethering complexes have been isolated (Scorrano et al., 2019) and many of them contain the integral ER-membrane proteins, VAP-A and -B (Lev et al., 2008).

VAP proteins interact via their major sperm protein (MSP) domain with FFAT motif-containing proteins, including the LTPs CERT, OSBP (oxysterol-binding protein 1) and Nir2 (Hanada, 2006; Peretti et al., 2008), and play major roles in MCSs formation between the ER and other cellular membranes (Murphy and Levine, 2016). Nevertheless, VAPs depletion has no profound effects on cell viability and contacts between ER and other organelles (Stoica et al., 2014; Dong et al., 2016), implying that other proteins are involved. Indeed, many tether proteins have been identified in the last few years, including the ERanchored protein MOSPD2 (motile sperm domain-containing protein 2), which also interacts with FFAT-containing proteins and is implicated in MCSs formation (Di Mattia et al., 2018). Notably, MOSPD2 and VAP proteins have been shown to interact and possibly form hetero-oligomers (Huttlin et al., 2017).

The molecular components of the different MCSs, their function in communication and metabolic exchanges, make MCSs a subject of great interest in cellular signaling and metabolism in both physiological conditions and pathological contexts, such as cancer and neurodegeneration. Here, we address the features of specific types of MCSs (involving mitochondria, endosomes, and lysosomes) with a focus on their role as key platforms for calcium signaling and lipid transfer, especially in cancer.

\section{MITOCHONDRIA-ASSOCIATED ER MEMBRANES (MAM) AND ITS ROLE IN CANCER}

Mitochondria-associated ER membranes (MAM) specific MCSs that create an intimate communication between ER and mitochondria and generate micro-domains in which the concentration of $\mathrm{Ca}^{2+}$ is much higher than the cytosol (Csordás et al., 2010), allowing for rapid mitochondrial $\mathrm{Ca}^{2+}$ uptake through the low affinity (KD of 20-30 $\mu \mathrm{M}$ ) channel of the mitochondrial calcium uniporter (MCU) (Baughman et al., 2011; De Stefani et al., 2011). Calcium uptake through the MCU complex covers essential roles in regulating energy status, signaling events and survival (Mammucari et al., 2016; Penna et al., 2018).

In the mitochondrial matrix, $\mathrm{Ca}^{2+}$ controls the activity of the three dehydrogenases of the Krebs cycle and, thus, the overall synthesis of ATP. Cancer cells, which require high energy for growth, commonly turn their energy production from oxidative phosphorylation to glycolysis (Warburg effect) (Schwartz et al., 2017). Although the amount of ATP produced via glycolysis is lower than through oxidative phosphorylation, it provides a selective advantage to cancer cells due to significantly higher glycolytic rate, supporting tumor growth and progression. Such a metabolic switch from aerobic metabolism to glycolysis has been linked to alterations of $\mathrm{Ca}^{2+}$ signaling at the MAM (Bittremieux et al., 2016). Dysregulation of calcium import at MAM can therefore severely affect tumorigenesis through two critical mechanisms: cellular metabolism and cell death pathways (Figure 3).

The current concept is that $\mathrm{Ca}^{2+}$ overload in the mitochondria leads to apoptosis, whereas basal level of $\mathrm{Ca}^{2+}$ enhances tumorigenesis. Indeed, several compounds with anti-tumor activity act by promoting mitochondrial calcium overload and consequently cell death, which can be inhibited by MCU blockers (Garcia-Prieto et al., 2013; Madreiter-Sokolowski et al., 2016). Likewise, inhibition of mitochondrial $\mathrm{Ca}^{2+}$ uptake enhances resistance to apoptotic stimuli in colon, cervical and prostate cancers, and increases cancer cell survival (Cui et al., 2019). However, in MDA-MB-231 breast carcinoma, MCU downregulation reduced tumor growth and metastasis, implying that mitochondrial $\mathrm{Ca}^{2+}$ uptake enhanced tumorigenesis of some cancers (Tosatto et al., 2016).

Calcium is released from the ER through the $\mathrm{IP}_{3} \mathrm{R}$, which is tethered to the mitochondrial VDAC1 via the GRP75 linker (Szabadkai et al., 2006; Figure 5). Several oncogenes modulate $\mathrm{IP}_{3} \mathrm{R}$ activity by post-translational modification or direct interaction. Phosphorylation of $\mathrm{IP}_{3} \mathrm{R}$ by $\mathrm{AKT}$ inhibits $\mathrm{Ca}^{2+}$ release and protects cancer cells from apoptosis (Szado et al., 2007). Similarly, interaction with the anti-apoptotic proteins $\mathrm{Bcl}-2$ and $\mathrm{Bcl}-\mathrm{XL}$, which are frequently overexpressed in cancers (Delbridge et al., 2016), suppresses $\mathrm{ER} \mathrm{Ca}^{2+}$ release to prevent apoptosis (Huang et al., 2013; Monaco et al., 2015; Morciano et al., 2018).

Different tether proteins have been postulated for MAMs formation and maintenance (Figure 5). Homo- and heterotypic interaction of Mitofusin 1 (MFN1) and 2 (MFN2) was initially proposed as a tether for MAM (Figure 5; De Brito and Scorrano, 2008). Despite both Mitofusins are transmembrane GTPases involved in mitochondrial fusion, MFN1 is localized to the outer mitochondrial membrane, while MFN2 is found both in the ER and mitochondria, largely present at MAM (De Brito and Scorrano, 2008; Naon et al., 2016). High MFN2 level in cancer cells was proposed to increase MAM and enhance ER-mitochondria $\mathrm{Ca}^{2+}$ flux and hence, susceptibility to apoptosis (Gautier et al., 2016; Cui et al., 2019). Interestingly, MFN2 also physically interacts with PERK (protein kinase RNA-Like ER kinase) (Muñoz et al., 2013), which also functions as a tether at MAM extensions (Verfaillie et al., 2012). In cancer cells, PERK may promote or suppress tumor progression. In the mesenchymal subtype of TNBC, PERK signaling enhanced invasion and metastasis through interaction with the transcription factor CREB3L1 (cAMP responsive element binding protein 3 like 1) (Feng et al., 2017), and its knockdown inhibited growth of breast carcinoma in animal models by limiting redox homeostasis (Bobrovnikova-Marjon et al., 2010). 


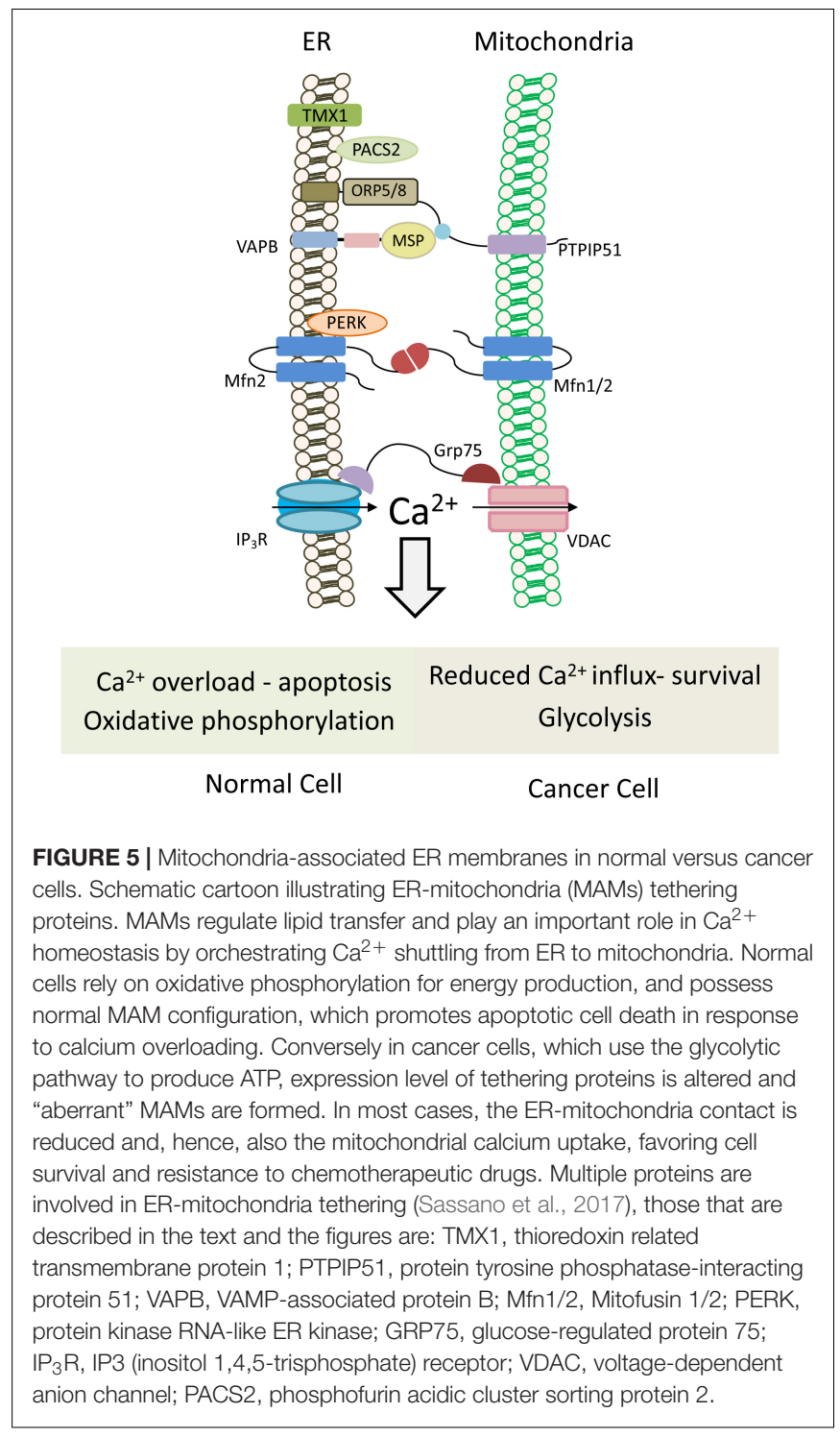

Phosphofurin acidic cluster sorting protein 2 (PACS-2) is a sorting protein that also functions as a MAM tether, and is involved in ER-mitochondria coupling (Simmen et al., 2005), as well as in apoptosis and survival. Apoptotic signals trigger its dephosphorylation and redistribution from the ER to mitochondria, recruiting Bid, followed by Bid cleavage and cell death (Simmen et al., 2005), while its phosphorylation by AKT promotes NF-kB (nuclear factor kappa-light-chainenhancer of activated B cells)-mediated pro-survival signaling (Betz et al., 2013).

Among the MAM proteins that regulate ER-mitochondria $\mathrm{Ca}^{2+}$ flux and affect cancer cells, are the redox-sensitive oxidoreductase thioredoxin related transmembrane protein 1 (TMX1) and protein tyrosine phosphatase-interacting protein 51 (PTPIP51). Reduced levels of TMX1 in cancer cells lead to increased ER $\mathrm{Ca}^{2+}$ levels, and a concomitant decrease in cytosolic and mitochondrial $\mathrm{Ca}^{2+}$ levels resulting in reduced mitochondrial respiration. This, in turn, makes the cancer cells more dependent on glycolysis, a hallmark of cancer cells (Ganapathy-kanniappan and Geschwind, 2013).

PTPIP51, an integral outer mitochondrial membrane (OMM) protein, interacts with VAP-B and is essential for VAP recruitment to MAM (Figure 5). It also interacts with the oxysterol-binding protein (OSBP)-related proteins ORP5 and ORP8, which transfer phosphatidylserine (PS) to the mitochondria for PE synthesis (Galmes et al., 2016). Depletion of PTPIP51 or VAP-B delays $\mathrm{Ca}^{2+}$ uptake by the mitochondria (De vos et al., 2012). Notably, both PTPIP51 and VAP have growth stimulatory activities, and high expression level of VAP-B in breast cancer enhanced cell growth in vitro and tumor growth in animal models (Rao et al., 2012).

Collectively, these examples demonstrate that many MAM proteins can influence tumor metabolism and/or apoptotic cell death and consequently may affect tumorigenesis or response to anti-cancer therapy.

\section{Lipids Modifications at the MAMs and Their Role in Cancer}

The role of MAM in the synthesis of specific lipids and their transfer to mitochondria was initially shown via cell fractionation (Vance, 1990; Vance and Canada, 1991). MAM is essential for the conversion of ER-derived PS to PE and for trafficking of cholesterol as a precursor for steroid species (Tatsuta et al., 2014).

Although mitochondria have low content of cholesterol compared to other organelles, cholesterol is enriched in MAMs compared to the rest of the ER and affects ER-mitochondria apposition (Sassano et al., 2017). In cancer cells, the inner mitochondrial membrane (IMM) has higher cholesterol content and phospholipids with shorter and more saturated acyl chains compared to normal cells. These lipid modifications decrease the IMM permeability, and consequently the vulnerability to apoptotic signals (Ribas et al., 2016).

Cardiolipin is a unique and abundant lipid of the IMM, accounts for $\sim 20 \%$ of the total lipid composition, which retains cytochrome $c$ in the IMM (Shidoji et al., 1999). Its accumulation in the IMM requires PA supply mediated by the PA-transfer activity of the TRIAP1/PRELI protein complexes. Depletion or inhibition of these protein complexes impairs cardiolipin accumulation and increases cell susceptibility to apoptosis (Potting et al., 2013). Hence, it could be that "aberrant" MAMs in cancer cells or abnormal expression of TRIAP1/PRELI would modulate cardiolipin levels and cytochrome $c$ release, and thus cell susceptibility to apoptosis that can be exploited for cancer therapy.

\section{ROLE OF ER-ENDOSOME AND ER-LYSOSOME CONTACT SITES IN HUMAN CANCER}

The endosomes undergo dynamic changes from biogenesis toward maturation. Endosome maturation is mediated by spatiotemporal phases, which regulate their size, location, uptake 
of macromolecules and sorting of cargos. The number of ERendosomes MCSs is markedly increased during maturation, reaching a maximum in the LE (Friedman et al., 2013; Hariri et al., 2016). We describe the functions of key proteins that are involved in ER-endosomes MCSs and their putative implications in cancer.

In addition to STARD3, the retromer subunit SNX2 (sorting nexin-2) also interacts with VAPs and tethers the ER membrane to endosomes (Dong et al., 2016). SNX2 binds PI(3)P on the endosomal surface, and affects the level of several cell surface proteins in cancer cells, including the c-Met receptor in lung and gastric cancer cells (Ogi et al., 2013). Depletion of VAPs leads to accumulation of PI4P in endosomes and disrupts endosome-toGolgi traffic. VAPs also interact with the ER proteins Protrudin and RTN3 (Reticulon protein 3), while Protrudin interacts with RAB11 (recycling endosomes), Rab7 (late endosomes) and $\mathrm{PI}(3) \mathrm{P}$ at the endosomes via its FYVE domain (Shirane and Nakayama, 2006; Matsuzaki et al., 2011). Overexpression of Protrudin increases ER-endosomes contacts (Raiborg et al., 2015), while resistance to endocrine therapies of breast cancer cells is associated with reduced levels of Protrudin (Magnani et al., 2013). Rab7 was also shown to be a marker of poor prognosis in melanoma cancer (Alonso-Curbelo et al., 2014). Whether Protrudin overexpression in cancer induces aberrant MCSs is currently unknown, but could be interesting to explore.

Another protein that functions at the ER-endosome MCSs is the ER-localized protein tyrosine phosphatase PTP1B which interacts with EGFR on early and late endosomes at the ERendosome MCSs (Eden et al., 2010). EGFR is implicated in various human cancers, while PTP1B can function either as an oncogene or tumor suppressor in various cancer types (Liu et al., 2015). At the ER-endosomes MCSs, PTP1B-EGFR interaction stabilizes MCSs, but it is not required for contact formation (Eden et al., 2010). As EGFR is highly expressed in many human cancers, it might stabilize aberrant ER-endosome MCSs to sustain endosomal signaling and prevent signaling termination by lysosomal degradation.

The lysosomes participate in many fundamental cellular processes, including recycling of cellular components, nutrientdependent signal transduction, membrane repair and pathogen defense signaling (Perera and Zoncu, 2016). Increased lysosomal activity, especially under nutrient deprivation, favors cancer growth and resistance to therapy in certain cancer types (Thelen and Zoncu, 2017). Lysosomes are considered as a central hub for sorting of lipids from endogenous and exogenous origin, and for maintenance of cholesterol homeostasis (Thelen and Zoncu, 2017). Another important property of the lysosomes is the close proximity of 5-20 nm with other organelles including the ER and mitochondria (Csordás et al., 2006; Phillips and Voeltz, 2016; Wong et al., 2018).

Lysosomes can process and distribute exogenous (LDLcholesterol) and endogenous (de novo synthesized in the ER) cholesterol through MCSs. The ER-anchored protein ORP5 and the membrane cholesterol transporter NPC1 (Niemann-Pick disease, type C1) interact and facilitate cholesterol export from lysosomes, whereas STARD3 in the LEs/Lys, through interactions with VAPs, mediates cholesterol transport from the ER to lysosomes (Thelen and Zoncu, 2017). ORP5 promotes cell proliferation and invasion via mTOR complex 1 (mTORC1) signaling ( $\mathrm{Du}$ et al., 2018), and its overexpression is associated with poor prognosis of pancreatic cancer (Koga et al., 2008). Interestingly, ORP5 and ORP8 were also localized to MAM (Gao and Yang, 2018), similar to the ER protein PDZD8 (PDZ domain-containing protein 8) (Hirabayashi et al., 2017), which was recently found at the ER-LEs/Lys contacts through interaction with Rab7 (Guillén-Samander et al., 2019). It was proposed to regulate $\mathrm{Ca}^{2+}$ dynamics in neurons and lipid transport between the ER and ER-LEs/Lys (Hirabayashi et al., 2017; Guillén-Samander et al., 2019).

In addition to cholesterol distribution, the ER-lysosome MCSs promote efficient $\mathrm{Ca}^{2+}$ transport between the two organelles. It is now clear that many functions of lysosomes depend on their ability to acquire calcium from the ER through $\mathrm{IP}_{3} \mathrm{Rs}$ and to release calcium (Atakpa et al., 2018). Lysosomal calcium release was proposed to be mediated by three types of channels: the mucolipin family of TRPML (transient receptor potential) channels, the two-pore (TPC) channels, and the transient receptor potential cation channels TRPVs (Raffaello et al., 2016; Li et al., 2019). Interestingly, TRPV4 is associated with poor prognosis in colon cancer (Liu et al., 2019) and is implicated in breast cancer metastasis (Lee et al., 2016). Similarly, TPCs have been found to be highly expressed in several cancers (Brailoiu et al., 2009; Jahidin et al., 2016) to facilitate cell migration and invasion (Nam et al., 2017).

ER-lysosome MCSs also play role in mTOR activation. mTOR is a central regulator of cell metabolism and growth, and is considered as a promising target for cancer therapy (Faes et al., 2017; Saxton and Sabatini, 2017). mTOR is activated at the LE/LY in response to multiple growth factors and amino-acid stimulation. Its activation is regulated by lysosomal positioning and is mediated by translocation of mTORC1-positive lysosomes to the cell periphery, where it remains in proximity of signaling receptors. It turns out that this translocation is regulated by ER-lysosome MCSs, and is mediated by two PI3-binding proteins: FYCO1 (FYVE and coiled-coil domain-containing protein 1) which is recruited to lysosomes, and the ER-resident protein Protrudin. PI3P-binding of FYCO1 and Protrudin promotes mTORC1 activation and concomitantly inhibits autophagy (Hong et al., 2017).

Overall, these findings suggest that ER-lysosome MCSs can affect fundamental properties of cancer cells including growth and metabolism, which may have aberrant configurations in cancer.

\section{CONCLUDING REMARKS}

In contrast to normal cells, cancer cells are characterized by distinct cellular metabolism and uncontrolled cell growth, migration and invasion. Many of these processes are influenced by lipids and calcium, two critical second messengers, which are 
regulated by LTPs and MCSs. LTPs can modulate the levels of lipid second messengers and thus can modify signaling pathways, signaling duration and termination. LTPs can also modulate the distributions of lipids, and consequently the stiffness, fluidity, and permeability of membranes, therefore affecting cell adhesion, receptor endocytosis and recycling, cell growth and migration as well as susceptibility to cancer therapy. Identification of specific LTPs that regulate these cellular processes which are aberrantly expressed in human cancer could be used for therapeutic intervention. Similarly, MCSs which affect lipid and calcium homeostasis, have an impact on cell proliferation and growth. On the other hand, calcium and certain lipids are involved in stress response and cell death pathways. The challenge is to switch off abnormal function or expression of LTPs in cancer cells and/or to direct "aberrant" MCSs toward cell death rather than cell proliferation, by manipulating the different tethering mechanisms that regulate MCSs formation and stability. Further studies on MCSs configuration and LTPs functions in cancer cells will be able to shed more light on how they may affect cell transformation and promote cancer development and metastasis.

\section{REFERENCES}

Alonso-Curbelo, D., Riveiro-Falkenbach, E., Pérez-Guijarro, E., Cifdaloz, M., Karras, P., Osterloh, L., et al. (2014). Article RAB7 controls melanoma progression by exploiting a lineage-specific wiring of the endolysosomal pathway. Cancer Cell 26, 61-76. doi: 10.1016/j.ccr.2014.04.030

Alpy, F., Boulay, A., Moog-Lutz, C., Andarawewa, K. L., Degot, S., Stoll, I., et al. (2003). Metastatic lymph node 64 (MLN64), a gene overexpressed in breast cancers, is regulated by Sp/KLF transcription factors. Oncogene 22, 3770-3780. doi: 10.1038/sj.onc. 1206500

Alpy, F., Rousseau, A., Schwab, Y., Legueux, F., Stoll, I., Wendling, C., et al. (2013). STARD3 or STARD3NL and VAP form a novel molecular tether between late endosomes and the ER. J. Cell Sci. 126, 5500-5512. doi: 10.1242/jcs.139295

Alpy, F., and Tomasetto, C. (2005). Give lipids a START: the StAR-related lipid transfer (START) domain in mammals. J. Cell Sci. 118, 2791-2801. doi: 10.1242/ jcs. 02485

Altomare, D. A., and Testa, J. R. (2005). Perturbations of the AKT signaling pathway in human cancer. Oncogene 24, 7455-7464. doi: 10.1038/sj.onc. 1209085

Amarilio, R., Ramachandran, S., Sabanay, H., and Lev, S. (2004). Differential regulation of endoplasmic reticulum structure through VAP-Nir protein interaction. J. Biol. Chem. 280, 5934-5944. doi: 10.1074/jbc.M409566200

Atakpa, P., Thillaiappan, N. B., Mataragka, S., Prole, D. L., and Taylor, C. W. (2018). IP3 receptors preferentially Associate with ER-Lysosome Contact Sites and Selectively Deliver Ca2+ to Lysosomes. Cell Rep. 25, 3180.e7-3193.e7. doi: 10.1016/j.celrep.2018.11.064

Balla, T. (2013). Phosphoinositides: tiny lipids with giant impact on cell regulation. Physiol. Rev. 93, 1019-1137. doi: 10.1152/physrev.00028.2012

Baughman, J. M., Perocchi, F., Girgis, H. S., Plovanich, M., Belcher-Timme, C. A., Sancak, Y., et al. (2011). Integrative genomics identifies MCU as an essential component of the mitochondrial calcium uniporter. Nature 476, 341-345. doi: 10.1038/nature10234

Betz, C., Stracka, D., Prescianotto-Baschong, C., Frieden, M., Demaurex, N., and Hall, M. N. (2013). MTOR complex 2-Akt signaling at mitochondriaassociated endoplasmic reticulum membranes (MAM) regulates mitochondrial physiology. Proc. Natl. Acad. Sci. U.S.A. 110, 12526-12534. doi: 10.1073/pnas. 1302455110

Bièche, I., Tomasetto, C., Régnier, C. H., Moog-Lutz, C., Rio, M. C., and Lidereau, R. (1996). Two distinct amplified regions at 17q11-q21 involved in human primary breast cancer. Cancer Res. 56, 3886-3890.

Bittremieux, M., Parys, J. B., Pinton, P., and Bultynck, G. (2016). ER functions of oncogenes and tumor suppressors: modulators of intracellular Ca $2+$ signaling.

\section{AUTHOR CONTRIBUTIONS}

DP wrote the text related to MCSs sections and incorporated the references. RT wrote the text on MCSs, mitochondrial function and related figure legends, and edited the manuscript. SK wrote on START family and prepared the related figure. SL was responsible for the other text sections, figures, and integrating the review. All authors listed have made a substantial, direct and intellectual contribution to the work, and approved it for publication.

\section{FUNDING}

SL is the incumbent of the Joyce and Ben B. Eisenberg Chair of Molecular Biology and Cancer Research. This work was supported by the Israel Science Foundation (ISF) (Grant No. 1530/17), by the ISF-NSFC Joint Research Program (Grant No. $2526 / 16)$, by the MDACC - SINF Grant, and by a research grant from David E. Stone.

Biochim. Biophys. Acta - Mol. Cell Res. 1863, 1364-1378. doi: 10.1016/j.bbamcr. 2016.01.002

Bobrovnikova-Marjon, E., Grigoriadou, C., Pytel, D., Zhang, F., Ye, J., Koumenis, C., et al. (2010). PERK promotes cancer cell proliferation and tumor growth by limiting oxidative DNA damage. Oncogene 29, 3881-3895. doi: 10.1038/onc. 2010.153

Brailoiu, E., Churamani, D., Cai, X., Schrlau, M. G., Brailoiu, G. C., Gao, X., et al. (2009). Essential requirement for two-pore channel 1 in NAADP-mediated calcium signaling. J. Cell Biol. 186, 201-209. doi: 10.1083/jcb.200904073

Brown, K. K., and Toker, A. (2015). The phosphoinositide 3-kinase pathway and therapy resistance in cancer. F1000Prime Rep. 7:13. doi: 10.12703/P7-13

Bunney, T. D., and Katan, M. (2010). Phosphoinositide signalling in cancer: beyond PI3K and PTEN. Nat. Rev. Cancer 10, 342-352. doi: 10.1038/nrc2842

Chang, C. L., Hsieh, T. S., Yang, T. T., Rothberg, K. G., Azizoglu, D. B., Volk, E., et al. (2013). Feedback regulation of receptor-induced $\mathrm{ca} 2+$ signaling mediated by e-syt 1 and nir2 at endoplasmic reticulum-plasma membrane junctions. Cell Rep. 5, 813-825. doi: 10.1016/j.celrep.2013.09.038

Chang, C. L., and Liou, J. (2015). Phosphatidylinositol 4, 5-bisphosphate homeostasis regulated by Nir2 and Nir3 proteins at endoplasmic reticulumplasma membrane junctions. J. Biol. Chem. 290, 14289-14301. doi: 10.1074/jbc. M114.621375

Clark, B. J. (2012). The mammalian START domain protein family in lipid transport in health and disease. J. Endocrinol. 212, 257-275. doi: 10.1530/JOE11-0313

Cockcroft, S., and Garner, K. (2012). 14-3-3 Protein and ATRAP bind to the soluble class IIB phosphatidylinositol transfer protein $\mathrm{RdgB} \beta$ at distinct sites. Biochem. Soc. Trans. 40, 451-456. doi: 10.1042/BST20110770

Cockcroft, S., and Garner, K. (2013). Potential role for phosphatidylinositol transfer protein (PITP) family in lipid transfer during phospholipase $\mathrm{C}$ signalling. $A d v$. Biol. Regul. 53, 280-291. doi: 10.1016/j.jbior.2013.07.007

Cohen, S., Valm, A. M., and Lippincott-Schwartz, J. (2018). Interacting organelles. Curr. Opin. Cell Biol. 53, 84-91. doi: 10.1016/j.ceb.2018.06.003

Csordás, G., Renken, C., Várnai, P., Walter, L., Weaver, D., Buttle, K. F., et al. (2006). Structural and functional features and significance of the physical linkage between ER and mitochondria. J. Cell Biol. 174, 915-921. doi: 10.1083/ jcb.200604016

Csordás, G., Várnai, P., Golenár, T., Roy, S., Purkins, G., Schneider, T. G., et al. (2010). Imaging interorganelle contacts and local calcium dynamics at the ERmitochondrial interface. Mol. Cell 39, 121-132. doi: 10.1016/j.molcel.2010.06. 029

Cui, C., Yang, J., Fu, L., Wang, M., and Wang, X. (2019). Progress in understanding mitochondrial calcium uniporter complex-mediated calcium signalling: a 
potential target for cancer treatment. Br. J. Pharmacol. 176, 1190-1205. doi: 10.1111/bph.14632

Delbridge, A. R., Grabow, S., Strasser, A., and Vaux, D. L. (2016). Thirty years of BCL-2: translating cell death discoveries into novel cancer therapies. Nat. Rev. Cancer 16, 99-109. doi: 10.1038/nrc.2015.17

De Brito, O. M., and Scorrano, L. (2008). Mitofusin 2 tethers endoplasmic reticulum to mitochondria. Nature 456, 605-610. doi: 10.1038/nature07534

De Craene, J. O., Bertazzi, D. L., Bär, S., and Friant, S. (2017). Phosphoinositides, major actors in membrane trafficking and lipid signaling pathways. Int. J. Mol. Sci. 18:634. doi: 10.3390/ijms18030634

De Stefani, D., Raffaello, A., Teardo, E., Szabó, I., and Rizzuto, R. (2011). A forty-kilodalton protein of the inner membrane is the mitochondrial calcium uniporter. Nature 476, 336-340. doi: 10.1038/nature10230

De vos, K. J., Mórotz, G. M., Stoica, R., Tudor, E. L., Lau, K. F., Ackerley, S., et al. (2012). VAPB interacts with the mitochondrial protein PTPIP51 to regulate calcium homeostasis. Hum. Mol. Genet. 21, 1299-1311. doi: 10.1093/hmg/ ddr559

Di Mattia, T., Wilhelm, L. P., Ikhlef, S., Wendling, C., Spehner, D., Nominé, Y., et al. (2018). Identification of MOSPD2, a novel scaffold for endoplasmic reticulum membrane contact sites. EMBO Rep. 19:e45453. doi: 10.15252/embr.20174 5453

Dong, R., Saheki, Y., Swarup, S., Lucast, L., Harper, J. W., and De Camilli, P. (2016). Endosome-ER Contacts Control Actin Nucleation and Retromer Function through VAP-Dependent Regulation of PI4P. Cell 166, 408-423. doi: 10.1016/j. cell.2016.06.037

Du, X., Zadoorian, A., Lukmantara, I. E., Qi, Y., Brown, A. J., and Yang, H. (2018). Oxysterol-binding protein-related protein 5 (ORP5) promotes cell proliferation by activation of mTORC1 signaling. J Biol Chem. 293, 3806-3818. doi: 10.1074/ jbc.RA117.001558

Durkin, M. E., Ullmannova, V., Guan, M., and Popescu, N. C. (2007a). Deleted in liver cancer 3 (DLC-3), a novel Rho GTPase-activating protein, is downregulated in cancer and inhibits tumor cell growth. Oncogene 26, 4580-4589. doi: 10.1038/sj.onc.1210244

Durkin, M. E., Yuan, B. Z., Zhou, X., Zimonjic, D. B., Lowy, D. R., Thorgeirsson, S. S., et al. (2007b). DLC-1:a Rho GTPase-activating protein and tumour suppressor: special review article. J. Cell. Mol. Med. 11, 1185-1207. doi: 10.1111/ j.1582-4934.2007.00098.x

Eden, E. R., White, I. J., Tsapara, A., and Futter, C. E. (2010). Membrane contacts between endosomes and ER provide sites for PTP1B-epidermal growth factor receptor interaction. Nat. Cell Biol. 12, 267-272. doi: 10.1038/ncb2026

Engelman, J. A. (2009). Targeting PI3K signalling in cancer: opportunities, challenges and limitations. Nat. Rev. Cancer. 9. 550-562. doi: 10.1038/nrc2664

Faes, S., Demartines, N., and Dormond, O. (2017). Resistance to mTORC1 inhibitors in cancer therapy: from kinase mutations to intratumoral heterogeneity of kinase activity. Oxid. Med. Cell Longev. 2017:1726078 doi: $10.1155 / 2017 / 1726078$

Fayngerts, S. A., Wu, J., Oxley, C. L., Liu, X., Vourekas, A., Cathopoulis, T., et al. (2014). TIPE3 is the transfer protein of lipid second messengers that promote cancer. Cancer Cell 26, 465-478. doi: 10.1016/j.ccr.2014.07.025

Feng, Y. X., Jin, D. X., Sokol, E. S., Reinhardt, F., Miller, D. H., and Gupta, P. B. (2017). Cancer-specific PERK signaling drives invasion and metastasis through CREB3L1. Nat. Commun. 8:1079. doi: 10.1038/s41467-017-01052-y

Friedman, J. R., Dibenedetto, J. R., West, M., Rowland, A. A., and Voeltz, G. K. (2013). Endoplasmic reticulum-endosome contact increases as endosomes traffic and mature. Mol. Biol. Cell. 24, 1030-1040. doi: 10.1091/mbc.E12-100733

Galmes, R., Houcine, A., Vliet, A. R., Agostinis, P., Jackson, C. L., and Giordano, F. (2016). ORP5/ORP8 localize to endoplasmic reticulum-mitochondria contacts and are involved in mitochondrial function. EMBO Rep. 17, 800-810. doi: 10.15252/embr.201541108

Ganapathy-kanniappan, S., and Geschwind, J.-F. (2013). Tumor glycolysis as a target for cancer therapy. Mol. Cancer 12:152. doi: 10.1186/1476-4598-12-152

Gao, M., and Yang, H. (2018). VPS13: a lipid transfer protein making contacts at multiple cellular locations. J. Cell Biol. 217, 3322-3324. doi: 10.1083/jcb. 201808151

Garcia-Prieto, C., Riaz Ahmed, K. B., Chen, Z., Zhou, Y., Hammoudi, N., Kang, Y., et al. (2013). Effective killing of leukemia cells by the natural product
OSW-1 through disruption of cellular calcium homeostasis. J. Biol. Chem. 288, 3240-3250. doi: 10.1074/jbc.M112.384776

García-Tuñón, I., Hernández-Sánchez, M., Ordoñez, J. L., Alonso-Pérez, V., Álamo-Quijada, M., Benito, R., et al. (2017). The CRISPR/Cas9 system efficiently reverts the tumorigenic ability of BCR/ABL in vitro and in a xenograft model of chronic myeloid leukemia. Oncotarget 8, 26027-26040. doi: 10.18632/ oncotarget.15215

Garner, K., Hunt, A. N., Koster, G., Somerharju, P., Groves, E., Li, M., et al. (2012). Phosphatidylinositol transfer protein, cytoplasmic 1 (PITPNC1) binds and transfers phosphatidic acid. J. Biol. Chem. 287, 32263-32276. doi: 10.1074/ jbc.M112.375840

Garner, K., Li, M., Ugwuanya, N., and Cockcroft, S. (2011). The phosphatidylinositol transfer protein $\operatorname{RdgB} \beta$ binds 14-3-3 via its unstructured C-terminus, whereas its lipid-binding domain interacts with the integral membrane protein ATRAP (angiotensin II type I receptor-associated protein). Biochem. J. 439, 97-111. doi: 10.1042/BJ20110649

Gautier, C. A., Erpapazoglou, Z., Mouton-Liger, F., Muriel, M. P., Cormier, F., Bigou, S., et al. (2016). The endoplasmic reticulum-mitochondria interface is perturbed in PARK2 knockout mice and patients with PARK2 mutations. Hum. Mol. Genet. 25, 2972-2984. doi: 10.1093/hmg/dd w148

Guillén-Samander, A., Bian, X., and de Camilli, P. (2019). PDZD8 mediates a Rab7-dependent interaction of the ER with late endosomes and lysosomes. Proc. Natl. Acad. Sci. U.S.A. 116, 22619-22623. doi: 10.1073/pnas.191350 9116

Halberg, N., Sengelaub, C. A., Navrazhina, K., Molina, H., Uryu, K., and Tavazoie, S. F. (2016). PITPNC1 recruits RAB1B to the golgi network to drive malignant secretion. Cancer Cell 29, 339-353. doi: 10.1016/j.ccell.2016. 02.013

Hanada, K. (2006). Discovery of the molecular machinery CERT for endoplasmic reticulum-to-Golgi trafficking of ceramide. Mol. Cell. Biochem. 286, 23-31. doi: 10.1007/s11010-005-9044-z

Hanada, K., Kumagai, K., Yasuda, S., Miura, Y., Kawano, M., Fukasawa, M., et al. (2003). Molecular machinery for non-vesicular trafficking of ceramide. Nature 426, 803-809. doi: 10.1038/nature02188

Hariri, H., Ugrankar, R., Liu, Y., and Mike Henne, W. (2016). Communicative \&amp; integrative biology inter-organelle ER-endolysosomal contact sites in metabolism and disease across evolution inter-organelle ER-endolysosomal contact sites in metabolism and disease across evolution. Commun. Integr. Biol. 9:e1156278 doi: 10.1080/19420889.2016.1156278

Heering, J., Weis, N., Holeiter, M., Neugart, F., Staebler, A., Fehm, T. N., et al. (2012). Loss of the ceramide transfer protein augments EGF receptor signaling in breast cancer. Cancer Res. 72, 2855-2866. doi: 10.1158/0008-5472.CAN-113069

Hirabayashi, Y., Kwon, S.-K., Paek, H., Pernice, W. M., Paul, M. A., Lee, J., et al. (2017). ER-mitochondria tethering by PDZD8 regulates Ca2+ dynamics in mammalian neurons. Science 358, 623-630. doi: 10.1126/science.aan 6009

Holthuis, J. C. M., and Levine, T. P. (2005). Lipid traffic: floppy drives and a superhighway. Nat. Rev. Mol. Cell Biol. 6, 209-220. doi: 10.1038/nrm 1591

Hong, Z., Pedersen, N. M., Wang, L., Torgersen, M. L., Stenmark, H., and Raiborg, C. (2017). PtdIns3P controls mTORC1 signaling through lysosomal positioning. J. Cell Biol. 216, 4217-4233. doi: 10.1083/jcb.201611073

Huang, H., Hu, X., Eno, C. O., Zhao, G., Li, C., and White, C. (2013). An Interaction between Bcl-x L and the Voltage-dependent Anion Channel (VDAC) Promotes Mitochondrial Ca 2 Uptake. J. Biol. Chem. 288, 19870-19881. doi: 10.1074/jbc. M112.448290

Huttlin, E. L., Bruckner, R. J., Paulo, J. A., Cannon, J. R., Ting, L., Baltier, K., et al. (2017). Architecture of the human interactome defines protein communities and disease networks. Nature 545, 505-509. doi: 10.1038/nature22366

Jahidin, A. H., Stewart, T. A., Thompson, E. W., Roberts-Thomson, S. J., and Monteith, G. R. (2016). Differential effects of two-pore channel protein 1 and 2 silencing in MDA-MB-468 breast cancer cells. Biochem. Biophys. Res. Commun. 477, 731-736. doi: 10.1016/j.bbrc.2016.06.127

Kawano, M., Kumagai, K., Nishijima, M., and Hanada, K. (2006). Efficient trafficking of ceramide from the endoplasmic reticulum to the golgi apparatus 
requires a VAMP-associated protein-interacting FFAT motif of CERT. J. Biol. Chem. 281, 30279-30288. doi: 10.1074/jbc.M605032200

Keinan, O., Kedan, A., Gavert, N., Selitrennik, M., Kim, S., Karn, T., et al. (2014). The lipid-transfer protein Nir2 enhances epithelial-mesenchymal transition and facilitates breast cancer metastasis. J. Cell Sci. 127 (Pt 21):4740-4749. doi: $10.1242 /$ jcs. 155721

Kim, H. J., Lee, S. Y., and Oh, S. C. (2016). The inositide signaling pathway as a target for treating gastric cancer and colorectal cancer. Front. Physiol. 7:168. doi: $10.3389 /$ fphys.2016.00168

Kim, S., Kedan, A., Marom, M., Gavert, N., Keinan, O., Selitrennik, M., et al. (2013). The phosphatidylinositol-transfer protein Nir2 binds phosphatidic acid and positively regulates phosphoinositide signalling. EMBO Rep. 14, 891-899. doi: 10.1038/embor.2013.113

Koga, Y., Ishikawa, S., Nakamura, T., Masuda, T., Nagai, Y., Takamori, H., et al. (2008). Oxysterol binding protein-related protein-5 is related to invasion and poor prognosis in pancreatic cancer. Cancer Sci. 99, 2387-2394. doi: 10.1111/j. 1349-7006.2008.00987.x

Kreitzburg, K. M., van Waardenburg, R. C. A. M., and Yoon, K. J. (2018). Sphingolipid metabolism and drug resistance in ovarian cancer. Cancer Drug Resist. 1, 181-197. doi: 10.20517/cdr.2018.06

Kunkel, G. T., MacEyka, M., Milstien, S., and Spiegel, S. (2013). Targeting the sphingosine-1-phosphate axis in cancer, inflammation and beyond. Nat. Rev. Drug Discov. 12, 688-702. doi: 10.1038/nrd4099

Lee, A. J. X., Roylance, R., Sander, J., Gorman, P., Endesfelder, D., Kschischo, M., et al. (2012). CERT depletion predicts chemotherapy benefit and mediates cytotoxic and polyploid-specific cancer cell death through autophagy induction. J. Pathol. 226, 482-494. doi: 10.1002/path.2998

Lee, W. H., Choong, L. Y., Mon, N. N., Lu, S., Lin, Q., Pang, B., et al. (2016). TRPV4 regulates breast cancer cell extravasation, stiffness and actin cortex. Sci. Rep. 6:27903. doi: $10.1038 /$ srep 27903

Lev, S. (2004). The role of the Nir/rdgB protein family in membrane trafficking and cytoskeleton remodeling. Exp. Cell Res. 297, 1-10. doi: 10.1016/j.yexcr.2004.02. 033

Lev, S. (2010). Non-vesicular lipid transport by lipid-transfer proteins and beyond. Nat Rev Mol Cell Biol.11, 739-750. doi: 10.1038/nrm2971

Lev, S. (2012). Nonvesicular lipid transfer from the endoplasmic reticulum. Cold Spring Harb. Perspect. Biol. 4:a013300. doi: 10.1101/cshperspect.a013300

Lev, S., Ben Halevy, D., Peretti, D., and Dahan, N. (2008). The VAP protein family: from cellular functions to motor neuron disease. Trends Cell Biol. 18, 282-290. doi: $10.1016 /$ j.tcb.2008.03.006

Levine, T. (2004). Short-range intracellular trafficking of small molecules across endoplasmic reticulum junctions. Trends Cell Biol. 14, 483-490. doi: 10.1016/j. tcb.2004.07.017

Levine, T. P. (2007). A lipid transfer protein that transfers lipid. J. Cell Biol. 179, 11-13. doi: $10.1083 /$ jcb. 200709055

Li, H., Tremblay, J. M., Yarbrough, L. R., and Helmkamp, G. M. (2002). Both isoforms of mammalian phosphatidylinositol transfer protein are capable of binding and transporting sphingomyelin. Biochim. Biophys. Acta Mol. Cell Biol. Lipids 1580, 67-76. doi: 10.1016/S1388-1981(01)00191-3

Li, M., Zhang, C.-S., Zong, Y., Feng, J.-W., Ma, T., Hu, M., et al. (2019). Transient receptor potential $\mathrm{V}$ channels are essential for glucose sensing by aldolase and AMPK. Cell Metab. 30:508.e12-524.e12. doi: 10.1016/j.cmet.2019.05.018

Liu, H., Wu, Y., Zhu, S., Liang, W., Wang, Z., Wang, Y., et al. (2015). PTP1B promotes cell proliferation and metastasis through activating src and ERK1/2 in non-small cell lung cancer. Cancer Lett. 359, 218-225. doi: 10.1016/j.canlet. 2015.01.020

Liu, X., Zhang, P., Xie, C., Sham, K. W. Y., Ng, S. S. M., Chen, Y., et al. (2019). Activation of PTEN by inhibition of TRPV4 suppresses colon cancer development. Cell Death Dis. 10:460. doi: 10.1038/s41419-019-1700-4

Long, J., Zhang, C.-J., Zhu, N., Du, K., Yin, Y.-F., Tan, X., et al. (2018). Lipid metabolism and carcinogenesis, cancer development. Am. J. Cancer Res. 8, $778-791$.

Luo, X., Zhao, X., Cheng, C., Li, N., Liu, Y., and Cao, Y. (2018). The implications of signaling lipids in cancer metastasis. Exp. Mol. Med. 50:127. doi: 10.1038/ s12276-018-0150- $\mathrm{x}$

Madreiter-Sokolowski, C. T., Gottschalk, B., Parichatikanond, W., Eroglu, E., Klec, C., Waldeck-Weiermair, M., et al. (2016). Resveratrol specifically kills cancer cells by a devastating increase in the $\mathrm{Ca} 2+$ coupling between the greatly tethered endoplasmic reticulum and mitochondria. Cell. Physiol. Biochem. 39, 1404-1420. doi: 10.1159/000447844

Magnani, L., Stoeck, A., Zhang, X., Lánczky, A., Mirabella, A. C., Wang, T. L., et al. (2013). Genome-wide reprogramming of the chromatin landscape underlies endocrine therapy resistance in breast cancer. Proc. Natl. Acad. Sci. U.S.A. 110. E1490-E1499. doi: 10.1073/pnas.1219992110

Mammucari, C., Raffaello, A., Vecellio Reane, D., and Rizzuto, R. (2016). Molecular structure and pathophysiological roles of the Mitochondrial Calcium Uniporter. Biochim Biophys Acta. 1863, 2457-2464. doi: 10.1016/j.bbamcr.2016. 03.006

Matsuzaki, F., Shirane, M., Matsumoto, M., and Nakayama, K. I. (2011). Protrudin serves as an adaptor molecule that connects KIF5 and its cargoes in vesicular transport during process formation. Mol. Biol. Cell 22, 4602-4620. doi: 10.1091/ mbc.E11-01-0068

van Meer, G. (1993). Transport and sorting of membrane lipids. Curr. Opin. Cell Biol. 5, 661-673. doi: 10.1016/0955-0674(93)90137-F

Monaco, G., Decrock, E., Arbel, N., van Vliet, A. R., La Rovere, R. M., De Smedt, H., et al. (2015). The BH4 Domain of Anti-apoptotic Bcl-XL, but Not That of the Related Bcl-2, Limits the Voltage-dependent Anion Channel 1 (VDAC1)mediated Transfer of Pro-apoptotic Ca 2 Signals to Mitochondria. J Biol Chem. 290, 9150-9161. doi: 10.1074/jbc.M114.622514

Moniz, L. S., and Vanhaesebroeck, B. (2014). A new TIPE of phosphoinositide regulator in cancer. Cancer Cell 26, 443-444. doi: 10.1016/j.ccell.2014.09.017

Morad, S. A. F., and Cabot, M. C. (2013). Ceramide-orchestrated signalling in cancer cells. Nat. Rev. Cancer 13, 51-65. doi: 10.1038/nrc3398

Morciano, G., Marchi, S., Morganti, C., Sbano, L., Bittremieux, M., Kerkhofs, M., et al. (2018). Role of mitochondria-associated ER membranes in calcium regulation in cancer-specific settings. Neoplasia 20, 510-523. doi: 10.1016/j.neo. 2018.03.005

Muñoz, J. P., Ivanova, S., Sánchez-Wandelmer, J., Martínez-Cristóbal, P., Noguera, E., Sancho, A., et al. (2013). Mfn2 modulates the UPR and mitochondrial function via repression of PERK. EMBO J. 32, 2348-2361. doi: 10.1038/emboj. 2013.168

Murai, T. (2015). Cholesterol lowering: role in cancer prevention and treatment. Biol. Chem. 396, 1-11. doi: 10.1515/hsz-2014-0194

Murphy, S. E., and Levine, T. P. (2016). VAP, a Versatile Access Point for the Endoplasmic Reticulum: Review and analysis of FFAT-like motifs in the VAPome. Biochim. Biophys. Acta Mol. Cell Biol. Lipids 1861, 952-961. doi: 10.1016/j.bbalip.2016.02.009

Nam, O., Nguyen, P., Grimm, C., Schneider, L. S., Chao, Y.-K., Atzberger, C., et al. (2017). Therapeutics, targets, and chemical biology two-pore channel function is crucial for the migration of invasive cancer cells. Cancer Res. 77, 1427-1438. doi: 10.1158/0008-5472.CAN-16-0852

Naon, D., Zaninello, M., Giacomello, M., Varanita, T., Grespi, F., Lakshminaranayan, S., et al. (2016). Critical reappraisal confirms that Mitofusin 2 is an endoplasmic reticulum-mitochondria tether. Proc. Natl. Acad. Sci. U.S.A. 113, 11249-11254. doi: 10.1073/pnas.1606786113

Ogi, S., Fujita, H., Kashihara, M., Yamamoto, C., Sonoda, K., Okamoto, I., et al. (2013). Sorting nexin 2-mediated membrane trafficking of c-Met contributes to sensitivity of molecular-targeted drugs. Cancer Sci. 104, 573-583. doi: 10.1111/ cas. 12117

Olayioye, M. A., Hoffmann, P., Pomorski, T., Armes, J., Simpson, R. J., Kemp, B. E., et al. (2004). The phosphoprotein StarD10 is overexpressed in breast cancer and cooperates with ErbB receptors in cellular transformation. Cancer Res. 64, 3538-3544. doi: 10.1158/0008-5472.CAN-03-3731

Olayioye, M. A., Vehring, S., Müller, P., Herrmann, A., Schiller, J., Thiele, C., et al. (2005). StarD10, a START domain protein overexpressed in breast cancer, functions as a phospholipid transfer protein. J. Biol. Chem. 280, 27436-27442. doi: 10.1074/jbc.M413330200

Penna, E., Espino, J., De Stefani, D., and Rizzuto, R. (2018). The MCU complex in cell death. Cell Calcium 69, 73-80. doi: 10.1016/j.ceca.2017.08.008

Perera, R. M., and Zoncu, R. (2016). The lysosome as a regulatory hub. Annu. Rev. Cell Dev. Biol. 32, 223-253. doi: 10.1146/annurev-cellbio-111315125125

Peretti, D., Dahan, N., Shimoni, E., Hirschberg, K., and Lev, S. (2008). Coordinated Lipid Transfer between the Endoplasmic Reticulum and the Golgi Complex Requires the VAP Proteins and Is Essential for Golgi-mediated Transport. Mol. Biol. Cell 19, 3871-3884. doi: 10.1091/mbc.E08-05-0498 
Perou, C. M., Sørile, T., Eisen, M. B., Van De Rijn, M., Jeffrey, S. S., Ress, C. A., et al. (2000). Molecular portraits of human breast tumours. Nature 406, 747-752. doi: $10.1038 / 35021093$

Phillips, M. J., and Voeltz, G. K. (2016). Structure and function of ER membrane contact sites with other organelles. Nat. Rev. Mol. Cell Biol. 17, 69-82. doi: 10.1038/nrm.2015.8

Png, K. J., Halberg, N., Yoshida, M., and Tavazoie, S. F. (2012). A microRNA regulon that mediates endothelial recruitment and metastasis by cancer cells. Nature 481, 190-196. doi: 10.1038/nature10661

Pollack, J. R., Perou, C. M., Alizadeh, A. A., Eisen, M. B., Pergamenschikov, A., Williams, C. F., et al. (1999). Genome-wide analysis of DNA copy-number changes using cDNA microarrays. Nat. Genet. 23, 41-46. doi: 10.1038/12640

Porter, K. R. (1953). Observations on a submicroscopic basophilic component of cytoplasm. J. Exp. Med. 97, 727-750. doi: 10.1084/jem.97.5.727

Potting, C., Tatsuta, T., Kö Nig, T., Haag, M., Wai, T., Aaltonen, M. J., et al. (2013). Cell metabolism TRIAP1/PRELI complexes prevent apoptosis by mediating intramitochondrial transport of phosphatidic acid. Cell Metab. 18, 287-295. doi: 10.1016/j.cmet.2013.07.008

Prestwich, G. D., Gajewiak, J., Zhang, H., Xu, X., Yang, G., and Serban, M. (2008). Phosphatase-resistant analogues of lysophosphatidic acid: agonists promote healing, antagonists and autotaxin inhibitors treat cancer. Biochim. Biophys. Acta Mol. Cell Biol. Lipids 1781, 588-594. doi: 10.1016/j.bbalip.2008.03.008

Prinz, W. A., Toulmay, A., and Balla, T. (2019). The functional universe of membrane contact sites. Nat. Rev. Mol. Cell Biol. doi: 10.1038/s41580-0190180-9 [Epub ahead of print].

Raffaello, A., Mammucari, C., Gherardi, G., and Rizzuto, R. (2016). Calcium at the center of cell signaling: interplay between endoplasmic reticulum, mitochondria, and lysosomes. Trends Biochem. Sci. 41, 1035-1049. doi: 10.1016/ j.tibs.2016.09.001

Raiborg, C., Wenzel, E. M., Pedersen, N. M., Olsvik, H., Schink, K. O., Schultz, S. W., et al. (2015). Repeated ER-endosome contacts promote endosome translocation and neurite outgrowth. Nature 520, 234-238. doi: 10.1038/ nature 14359

Rao, M., Song, W., Jiang, A., Shyr, Y., and Lev, S. (2012). VAMP-Associated Protein B (VAPB) Promotes Breast Tumor Growth by Modulation of Akt Activity. PLoS One 7:46281. doi: 10.1371/journal.pone.0046281

Ribas, V., García-Ruiz, C., and Fernández-Checa, J. C. (2016). Mitochondria, cholesterol and cancer cell metabolism. Clin. Transl. Med. 5:22 doi: 10.1186/ s40169-016-0106-5

Saheki, Y., and De Camilli, P. (2017). Endoplasmic reticulum-plasma membrane contact sites. Annu. Rev. Biochem. 86, 659-684. doi: 10.1146/annurev-biochem061516-044932

Sassano, M. L., van Vliet, A. R., and Agostinis, P. (2017). Mitochondria-associated membranes as networking platforms and regulators of cancer cell fate. Front. Oncol. 7:174. doi: 10.3389/fonc.2017.00174

Saxton, R. A., and Sabatini, D. M. (2017). mTOR Signaling in Growth, Metabolism, and Disease. Cell 168, 960-976. doi: 10.1016/j.cell.2017.02.004

Schenning, M., Van Tiel, C. M., Van Manen, D., Stam, J. C., Gadella, B. M., Wirtz, K. W. A., et al. (2004). Phosphatidylinositol transfer protein $\alpha$ regulates growth and apoptosis of NIH3T3 cells: involvement of a cannabinoid 1-like receptor. J. Lipid Res. 45, 1555-1564. doi: 10.1194/jlr.M400127-JLR200

Schwartz, L., Supuran, C., and Alfarouk, K. (2017). The warburg effect and the hallmarks of cancer. Anticancer. Agents Med. Chem. 17, 164-170. doi: 10.2174/ 1871520616666161031143301

Scorrano, L., De Matteis, M. A., Emr, S., Giordano, F., Hajnóczky, G., Kornmann, B., et al. (2019). Coming together to define membrane contact sites. Nat. Commun. 10:1287 doi: 10.1038/s41467-019-09253-3

Selitrennik, M., and Lev, S. (2016). The role of phosphatidylinositol-transfer proteins at membrane contact sites. Biochem. Soc. Trans. 44, 419-424. doi: 10.1042/BST20150182

Shidoji, Y., Hayashi, K., Komura, S., Ohishi, N., and Yagi, K. (1999). Loss of molecular interaction between cytochrome $c$ and cardiolipin due to lipid peroxidation. Biochem. Biophys. Res. Commun. 264, 343-347. doi: 10.1006/bbrc. 1999.1410

Shirane, M., and Nakayama, K. I. (2006). Protrudin induces neurite formation by directional membrane trafficking. Science 314, 818-821. doi: 10.1126/science. 1134027

Simmen, T., Aslan, J. E., Blagoveshchenskaya, A. D., Thomas, L., Wan, L., Xiang, Y., et al. (2005). PACS-2 controls endoplasmic reticulum-mitochondria communication and Bid-mediated apoptosis. EMBO J. 24, 717-729. doi: 10. 1038/sj.emboj.7600559

Soccio, R. E., and Breslow, J. L. (2003). StAR-related lipid transfer (START) proteins: mediators of intracellular lipid metabolism. J. Biol. Chem. 278, 22183 22186. doi: 10.1074/jbc.R300003200

Spiegel, S., and Milstien, S. (2003). Sphingosine-1-phosphate: an enigmatic signalling lipid. Nat. Rev. Mol. Cell Biol. 4, 397-407. doi: 10.1038/nrm 1103

Stoica, R., De Vos, K. J., Paillusson, S., Mueller, S., Sancho, R. M., Lau, K.-F., et al. (2014). ER-mitochondria associations are regulated by the VAPB-PTPIP51 interaction and are disrupted by ALS/FTD-associated TDP-43. Nat. Commun. 5:3996 doi: 10.1038/ncomms4996

Szabadkai, G., Bianchi, K., Várnai, P., De Stefani, D., Wieckowski, M. R., Cavagna, D., et al. (2006). Chaperone-mediated coupling of endoplasmic reticulum and mitochondrial Ca 2+ channels. J. Cell Biol. 175, 901-911. doi: 10.1083/jcb. 200608073

Szado, T., Vanderheyden, V., Parys, J. B., De Smedt, H., Rietdorf, K., Kotelevets, L., et al. (2007). The Babraham Institute. Available at: www.pnas.orgcgi (Accessed July 9, 2019).

Tatsuta, T., Scharwey, M., and Langer, T. (2014). Mitochondrial lipid trafficking. Trends. Cell. Biol. 24, 44-52. doi: 10.1016/j.tcb.2013.07.011

Thelen, A. M., and Zoncu, R. (2017). Emerging roles for the lysosome in lipid metabolism. Trends Cell Biol. 27, 833-850. doi: 10.1016/j.tcb.2017. 07.006

Toker, A. (2002). Phosphoinositides and signal transduction. Cell. Mol. Life Sci. 59, 761-779. doi: 10.1007/s00018-002-8465-z

Tomasetto, C., Régnier, C., Moog-Lutz, C., Mattei, M. G., Chenard, M. P., Lidereau, R., et al. (1995). Identification of four novel human genes amplified and overexpressed in breast carcinoma and localized to the q11-q21.3 region of chromosome 17. Genomics 28, 367-376. doi: 10.1006/geno.1995. 1163

Tosatto, A., Sommaggio, R., Kummerow, C., Bentham, R. B., Blacker, T. S., Berecz, T., et al. (2016). The mitochondrial calcium uniporter regulates breast cancer progression via HIF-1a. EMBO Mol Med 8, 569-585. doi: 10.15252/emmm. 201606255

Van Meer, G., Voelker, D. R., and Feigenson, G. W. (2008). Membrane lipids: where they are and how they behave. Nat. Rev. Mol. Cell Biol. 9, 112-124. doi: $10.1038 / \mathrm{nrm} 2330$

Vance, E. (1990). Phospholipid mitochondria synthesis in a membrane fraction associated identified. J. Biol. Chem. 265, 7248-7257.

Vance, J. E., and Canada, A. T. G. (1991). Newly made phosphatidylserine and phosphatidylethanolamine are preferentially translocated between rat liver mitochondria and endoplasmic reticulum. J. Biol. Chem. 266, 89-97.

Vassilev, B., Sihto, H., Li, S., Hölttä-Vuori, M., Ilola, J., Lundin, J., et al. (2015). EPITHELIAL AND MESENCHYMAL CELL BIOLOGY Elevated Levels of StAR-Related Lipid Transfer Protein 3 Alter Cholesterol Balance and Adhesiveness of Breast Cancer Cells Potential Mechanisms Contributing to Progression of HER2-Positive Breast Cancers. Am. J. Pathol. 185, 987-1000. doi: 10.1016/j.ajpath.2014.12.018

Verfaillie, T., Rubio, N., Garg, A. D., Bultynck, G., Rizzuto, R., Decuypere, J.P., et al. (2012). PERK is required at the ER-mitochondrial contact sites to convey apoptosis after ROS-based ER stress. Cell Death Differ. 19, 1880-1891. doi: $10.1038 / \mathrm{cdd} .2012 .74$

Vincent-Salomon, A., Lucchesi, C., Gruel, N., Raynal, V., Pierron, G., Goudefroye, R., et al. (2008). Integrated genomic and transcriptomic analysis of ductal carcinoma in situ of the breast. Clin. Cancer Res. 14, 1956-1965. doi: 10.1158/ 1078-0432.CCR-07-1465

Wilhelm, L. P., Wendling, C., Védie, B., Kobayashi, T., Chenard, M., Tomasetto, C., et al. (2017). STARD 3 mediates endoplasmic reticulum-to-endosome cholesterol transport at membrane contact sites. EMBO J. 36, 1412-1433. doi: 10.15252/embj.201695917

Wirtz, K. W. A. (1974). Transfer of phospholipids between membrane. Biochim. Biophys. Acta Rev. Biomembr. 344, 95-117. doi: 10.1016/0304-4157(74)90 001-X

Wirtz, K. W. A., Devaux, P. F., and Bienvenue, A. (1980). Phosphatidylcholine exchange protein catalyzes the net transfer of phosphatidylcholine to model membranes. Biochemistry 19, 3395-3399. doi: 10.1021/bi005 $55 \mathrm{a} 046$ 
Wong, L. H., Gatta, A. T., and Levine, T. P. (2019). Lipid transfer proteins: the lipid commute via shuttles, bridges and tubes. Nat. Rev. Mol. Cell Biol. 20, 85-101. doi: 10.1038/s41580-018-0071-5

Wong, Y. C., Ysselstein, D., and Krainc, D. (2018). Mitochondria-lysosome contacts regulate mitochondrial fission via RAB7 GTP hydrolysis. Nature 554, 382-386 doi: 10.1038/nature25486

Yadav, S., Garner, K., Georgiev, P., Li, M., Gomez-Espinosa, E., Panda, A., et al. (2015). RDGB $\alpha$, a PtdIns-PtdOH transfer protein, regulates G-proteincoupled PtdIns(4,5)P2 signalling during Drosophila phototransduction. J. Cell Sci. 128, 3330-3344. doi: $10.1242 /$ jcs. 173476

Yamaji, T., and Hanada, K. (2014). Establishment of HeLa cell mutants deficient in sphingolipid-related genes using TALENs. PLoS One 9:e88124 doi: 10.1371/ journal.pone.0088124

Yamaji, T., and Hanada, K. (2015). Sphingolipid metabolism and interorganellar transport: localization of sphingolipid enzymes and lipid transfer proteins. Traffic 16, 101-122. doi: 10.1111/tra.12239
Zilversmit, D. B. (1983). Lipid transfer proteins: overview and applications. Methods Enzymol. 98, 565-573. doi: 10.1016/0076-6879(83)98 $183-1$

Conflict of Interest: SK was employed by company Nakseongdae R\&D Center.

The remaining authors declare that the research was conducted in theabsence of any commercial or financial relationships that could be construed asa potential conflict of interest.

Copyright (c) 2020 Peretti, Kim, Tufi and Lev. This is an open-access article distributed under the terms of the Creative Commons Attribution License (CC BY). The use, distribution or reproduction in other forums is permitted, provided the original author(s) and the copyright owner(s) are credited and that the original publication in this journal is cited, in accordance with accepted academic practice. No use, distribution or reproduction is permitted which does not comply with these terms. 